\title{
Impact of Transport Network Changes on Tourism in Protected Areas: A Case Study of Ayubia National Park, Pakistan
}

\author{
Muhammad Shaker*, Muhammad Adnan, Elke Hermans, Ansar Yasar, Geert Wets \\ UHasselt - Universiteit Hasselt, Transportation Research Institute (IMOB), Diepenbeek, Belgium \\ Email: ^muhammad.shaker@uhasselt.be,muhammad.adnan@uhasselt.be,elke.hermans@uhasselt.be, ansar.yasar@uhasselt.be, \\ geert.wets@uhasselt.be
}

How to cite this paper: Shaker, M., Adnan, M., Hermans, E., Yasar, A. and Wets, G. (2020) Impact of Transport Network Changes on Tourism in Protected Areas: A Case Study of Ayubia National Park, Pakistan. Journal of Transportation Technologies, 10, 325-350.

https://doi.org/10.4236/jtts.2020.104021

Received: August 29, 2020

Accepted: September 25, 2020

Published: September 28, 2020

Copyright (อ 2020 by author(s) and Scientific Research Publishing Inc. This work is licensed under the Creative Commons Attribution International License (CC BY 4.0).

http://creativecommons.org/licenses/by/4.0/

\begin{abstract}
The inflow caused by tourists in peak seasons exerts an uncontrollable pressure on the existing infrastructure. The Ayubia National Park in Pakistan faces traffic delays and capacity restraints on the connecting roads in peak season. The study focuses on the formulation of critical strategies by deploying amendments in the transport network. The methodology contains three parts: 1) a questionnaire was designed to inquire about several variables from the visitors; 2) the second part was traffic count data collection and analysis. Based on the response collected, the impact of multiple strategies on the network was analyzed using TransCad; 3 ) in the third part, the results obtained were shared with experts to gain their valuable opinions. It was observed that the time of the day based access restriction to heavy vehicles could lead to dropping the Volume to capacity ratio from 1.7 to 1.2. However, The experts were also of the view that network changes can enhance and improve the visitors' experience.
\end{abstract}

\section{Keywords}

Transport, Management, National Park, Tourism, Strategies, Visitors

\section{Introduction}

Tourism has a significant effect on environmental, cultural, social, and economic values and in terms of the economy considered as an industry. The complex nature of tourism and its bonding with the surrounding neighbourhood is essential for the improvement in the economy [1]. It has been observed that nature-based tourism, especially parks and protected areas (PAs), has grown in recent years. 
An increase in tourist activity increases the burden of maintenance activities to sustain the place. Moreover, the surrounding transportation system requires attention to ascertain fast and easy access [2] [3]. An appropriately functioning transportation network can improve the tourists' experiences, where the occurrence of congestion, accidents, and pollution is lower [4]. Previous researches carried out to improve the transportation around PAs have focused on tourists' experiences, satisfaction, and visitors' mobility pattern [5] [6]. The traffic volume around protected areas is estimated to increase, as these are consequences of the increase in the number of tourists. The inflow of a large number of tourists causes discomfort and reduces the safety on the roads heading towards protected areas [7].

The inflow of a large number of private vehicles on to the roads connecting to the protected areas highly depends upon the availability of infrastructure and operational strategy in the surrounding cities and counties. The lack of frequent public transport services is a strong reason behind the preference of private vehicles, which results in operational traffic issues around PAs [8]. Traffic congestion around protected areas may occur because of the high volume of motorized vehicles, lesser road capacities, traffic disorder, and an insufficient number of parking spots. A very few studies have focused on the element of seasonal congestion around the protected areas [8]. Many of the protected areas around the globe are facing problems, for example, 1) ever-growing crowds around Acadia National Park, 2) increasing waiting times at entrance stations, shuttle lines and parking shortage at Grand Canyon National Park, Arizona, 3) congestion around connecting roads of Rocky Mountain National Park, Colorado in summer and early fall, 4) traffic jams and parking problems at Glacier National Park, Montana and Yellowstone National Park in Wyoming [9]. Underdeveloped and developing countries are facing similar problems as mentioned above and protected areas require a lot of attention and research activity to improve the overall transport in the upcoming years. In fact, the situation is not different at all compared to developed countries like England, where they are also facing problems like congestion, bad connectivity and infrequency of public transport around their protected areas [10]. The national parks of Pakistan located close to and within urban communities are also facing traffic problems, especially in peak seasons. To further investigate and understand the mobility problems around the protected areas of Pakistan, a case study of Ayubia National Park located in Pakistan, is selected. Further details about case study are presented in Section 1.1 .

There are multiple techniques/strategies adapted by various authorities to control the traffic problems around National Parks around the world. For example, congestion pricing is considered as the most effective mechanism by controlling authorities to alleviate traffic congestion [11]. Congestion pricing has a big plus over other traffic management policies as it encourages travellers to adjust all aspects of their behaviour: mode of transport, number of trips, destination, time of day, route, hotels' location and workplace [12]. 
In some other techniques, for example, for traffic management, the key step is the restriction of private vehicles by giving access to a hierarchical use of basic (approaching trips) and secondary (internal trips) road networks. Around 30 years ago, the restrictions for the heavy vehicle applied in the case study of the UK by restricting the heavy vehicles for a certain duration of time in various contexts [13] for example, on a weight limitation basis: $7.5 \mathrm{t}$ along main access routes, 5t along minor access routes and $2 t$ on the internal local routes network [14].

The case study selected has the potential to attract a large volume of tourists, which is economically feasible for the local community and also for the government. This study provides feasible and economical solutions to not only overcome the traffic congestion but also to facilitate the tourists. The study evaluates the application of multiple strategies based on visitors' responses towards strategies, traffic assignment model results, and lastly, the experts' opinion to the most feasible measure. The study differs from past studies, as it combines the local perspective towards the suggestive literature measure and then further cross verify the applicability from the experts involved in the policymaking process of Ayubia National Park.

\section{Case Study}

Ayubia National Park (ANP), a classic example of a traditional national park model, termed as the "Golden Era National Park by Eagles (2009). Ownership of land and gardens belongs to the government of Khyber Pakhtunkhwa. According to the International Union for Conservation of Nature (IUCN) standards, the park is classified in category V, in protected landscapes type 15 [15]. Ayubia National Park was established in 1984 under the provisions of the Khyber Pakhtunkhwa Wildlife Act of 1975, with the aim of strengthening and preserving its distinctive panorama, flora, and fauna in its natural state. It was originally established on 1683 hectares of land, but the area was expanded to 3,312 hectares in 1998. During the summer season, this park attracts thousands of visitors because of the cold climate and pristine nature - forests, and wildlife [16]. Geographically, the park is located in the Himalayas between latitudes $34^{\circ} 1^{\prime}$ to $34^{\circ} 3.8^{\prime} \mathrm{N}$ latitude and $73^{\circ} 22.8^{\prime}$ to $73^{\circ} 27.1^{\prime} \mathrm{E}$ longitude (see Figure 1). The park represents the pine forests of the pine Western Himalayas, part of the temperate forests of the western Himalayas [17]. The height and lowest points of the park vary from about $1050 \mathrm{~m}$ at Lahur to $3027 \mathrm{~m}$ at the top of Miranjani [18]. The park is easily accessible by a road from Abbottabad and Islamabad via Murree, using Abbottabad Road, which also features the western boundary of the park [16].

In non-peak seasons, the park is easily accessible. However, in the case of seasonal tourism and during the holidays of religious events (EID festivals, Christmas, etc.), the region attracts a large amount of traffic. The Ayubia National Park, because of its beautiful nature and everlasting vista, attracts a large number of tourists from the surrounding cities. The reason for the selection of this case study is that the surrounding roads are overcrowded because of additional traffic 

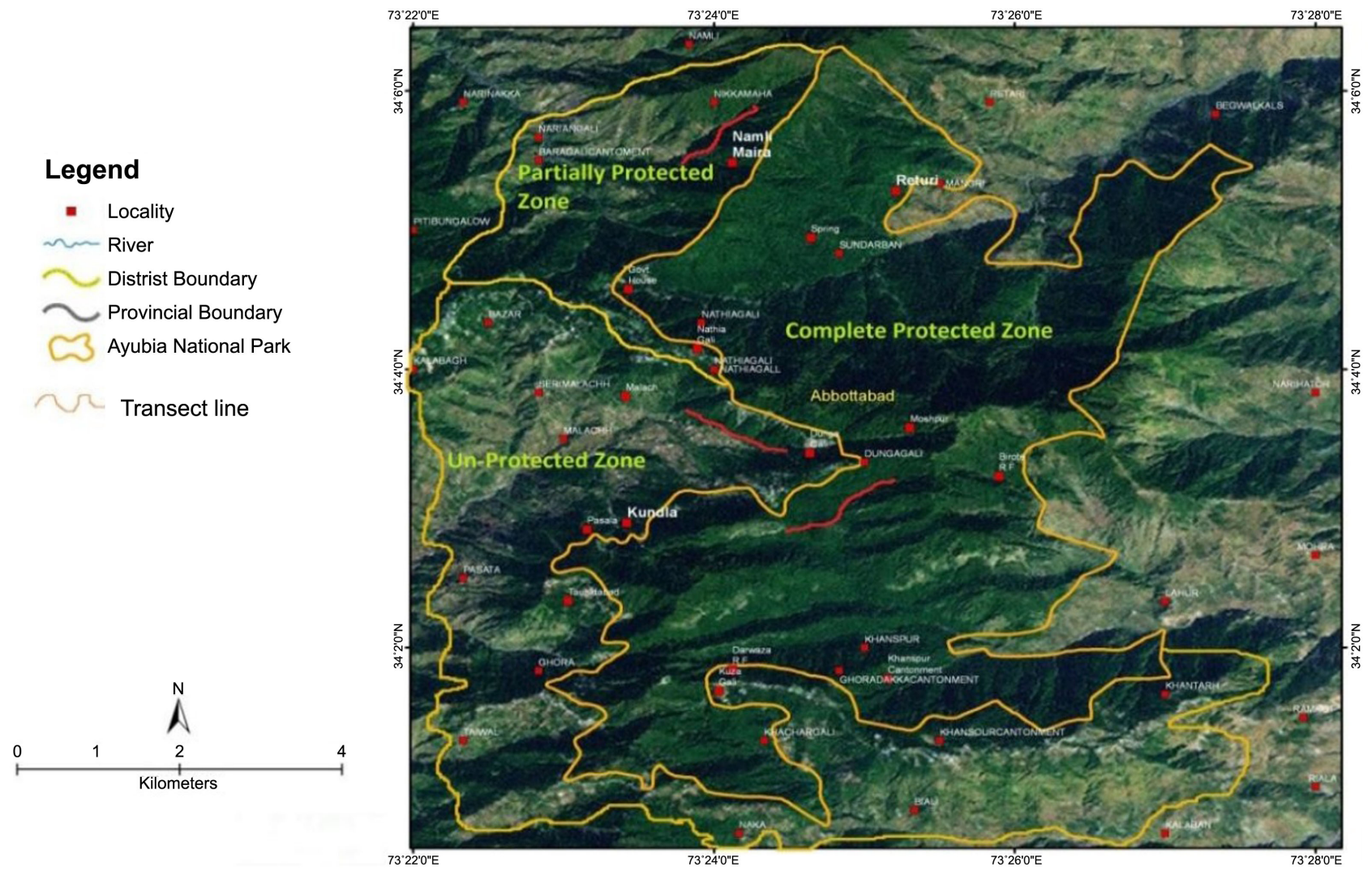

Figure 1. Satellite image of Ayubia National Park showing physical features and district boundaries [19].

generated by tourism. The next section highlights the detailed issues that need to be tackled to enhance mobility towards the ANP.

\section{Problem Statement}

The problematic situation comprises of various issues that require special attention. 1) The traffic and the infrastructure facilities around Ayubia park are hardly sufficient to meet the need; according to the city's traffic police up to 17,000 vehicles enter on connecting roads of Ayubia National Park on a daily basis, which is certainly too many [20]. Moreover, when there are seasonal holidays and bulk of traffic starts moving towards the national park, this huge volume of tourists creates congestion, decreases the travel flow and also increases the volume to capacity ratio [21]. According to news sources on $9^{\text {th }}$ June 2016, about 70,000 cars entered Murree (one of the access points to Ayubia National Park) in one day [22]. 2) Insufficient supply of public transport pushes tourists to hire personal cars and private cabs. According to one of the research, $23 \%$ of the people drive without a license in Pakistan [23]. The vehicles (either personal or rented) driven occasionally for the tourism purpose do not have vehicle inspection and maintenance certificate, which means these cars can stop working at any time on the road and could disturb the flow of traffic. The intensity of the problem increases if these elements combine, i.e., no license and no inspection certificate. An increase in personal car usage causes huge congestion to the con- 
nected roads of ANP. During the peak season (summer period and in winter vacations), there is an abrupt increase in the number of tourists. The traditional parking spots around scenic points are not able to accommodate the burden of private cars ensued from a holiday period [24]. Indeed, the research question is as mentioned: What would be the impact of managing the traffic volume to improve mobility on connected roads around Ayubia National Park?

\section{Research Methodology}

The case study contains unique local problems, so, in order to solve these problems, different analyses are being incorporated. The first step was the identification of data to be collected to investigate the problem. The data collection process was divided into two categories, primary and secondary data. The primary data was collected using the questionnaire technique, containing the important attributes and possible network changes/strategies, as identified in the literature. The revealed preference technique was used to investigate the multiple characteristics of stakeholders and their willingness towards the adoption of assumed strategies. The secondary data relates to the traffic counts, volume, and OD matrix. The secondary data was collected from the National Transport Research Center (NTRC) in Pakistan. The data collection based on the questionnaire was used for descriptive analysis and to determine the visitors'officials' response towards the adoption of the assumed policy/strategies. The response collected from the visitors helped in the extraction of preferences towards the assumptions. The secondary data was used to determine the impact of necessary changes by application of assumptions being inquired in a questionnaire from the visitors and officials; for this purpose, Transcad software was used. The data collection process is further explained in detail in Section 3.1. The step-wise methodological process is explained in Figure 2. The first step was the identification of traffic analysis zones; the zones were selected based on the purpose and traffic volume being exerted towards the national park. 2) The second step was the relevant data extraction and data modification from the raw data. 3) the third step was the implication of possible strategies. Based on the results obtained from the questionnaire, the first three preferred strategies by the respondents were selected: restriction of vehicles (without inspection and maintenance certificate), application of toll at certain entry to exit locations and creation of permissible time windows for allowing access to heavy vehicles. These strategies were applied to the transport network using Transcad software. 4) The next step was to interpret and compare the effect of the implementation of different scenarios on the volume to capacity ratio and also on the travel free flow of the connected network. 5) To further inquire, the results of the analysis carried out in Transcad were presented to the officials associated with the Ayubia National Park, and their response was collected using the Delphi method. 6) The final step is the deduction of the most effective policy recommendations based an all results. The methodology layout is shown in Figure 2. 


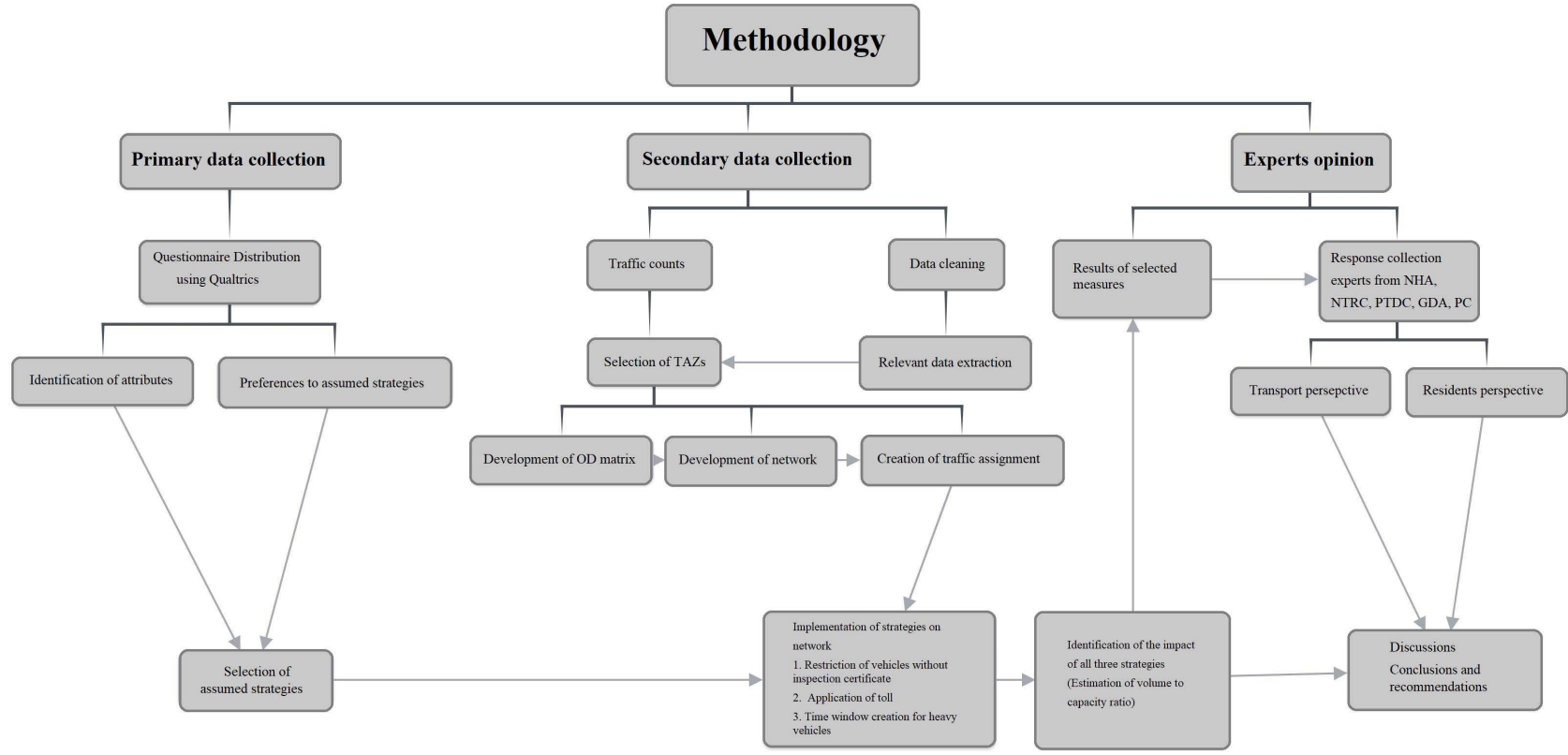

Figure 2. Step by step approach to complete the research.

\section{Data Collection}

The primary data collection was carried out using a questionnaire. A questionnaire was designed to inquire about a number of variables for example mode of transport used to travel to the national park, opinion about the level of congestion, availability of parking space, the status of parking, effect of defective vehicles, duration of stay, distance from the park and frequency of visit. The respondents were asked to select, in their opinion, the most suitable strategies, keeping in mind the local perspective and being tourists. The questionnaire was distributed to the population of those who had at least once visited the park. Two methods were used to gain the responses: social media pages and distribution to the concerned departments via officials sources. The questionnaire was distributed, and the response was collected in the period of the $12^{\text {th }}$ of August 2019 till $23^{\text {rd }}$ of December 2019. A total of 176 respondent responses were analyzed.

Traffic analysis zones (TAZs) and the network was selected based on the trip generation and proximity to the Ayubia National park (see Figure 3). The selection of the TAZs was based on the flow generated from these zones towards the Ayubia National Park. The names of the selected zones are Rawalpindi (6), Islamabad (3), Muzaffarabad (7), Murree (5), Abbottabad (1), Haripur (2), and Mansehra (4). These numbers represent the coding assigned for OD matrix

The data collected from NTRC for the research is mentioned as under in Table 1. Based on this data, traffic analysis zones were created and network (major roads) was developed.

Table 2 is the OD matrix developed based on all the data available. Origin to destination matrix was created based on the data collected from the National Transportation and Research Centre (NTRC), Pakistan. The required data for 


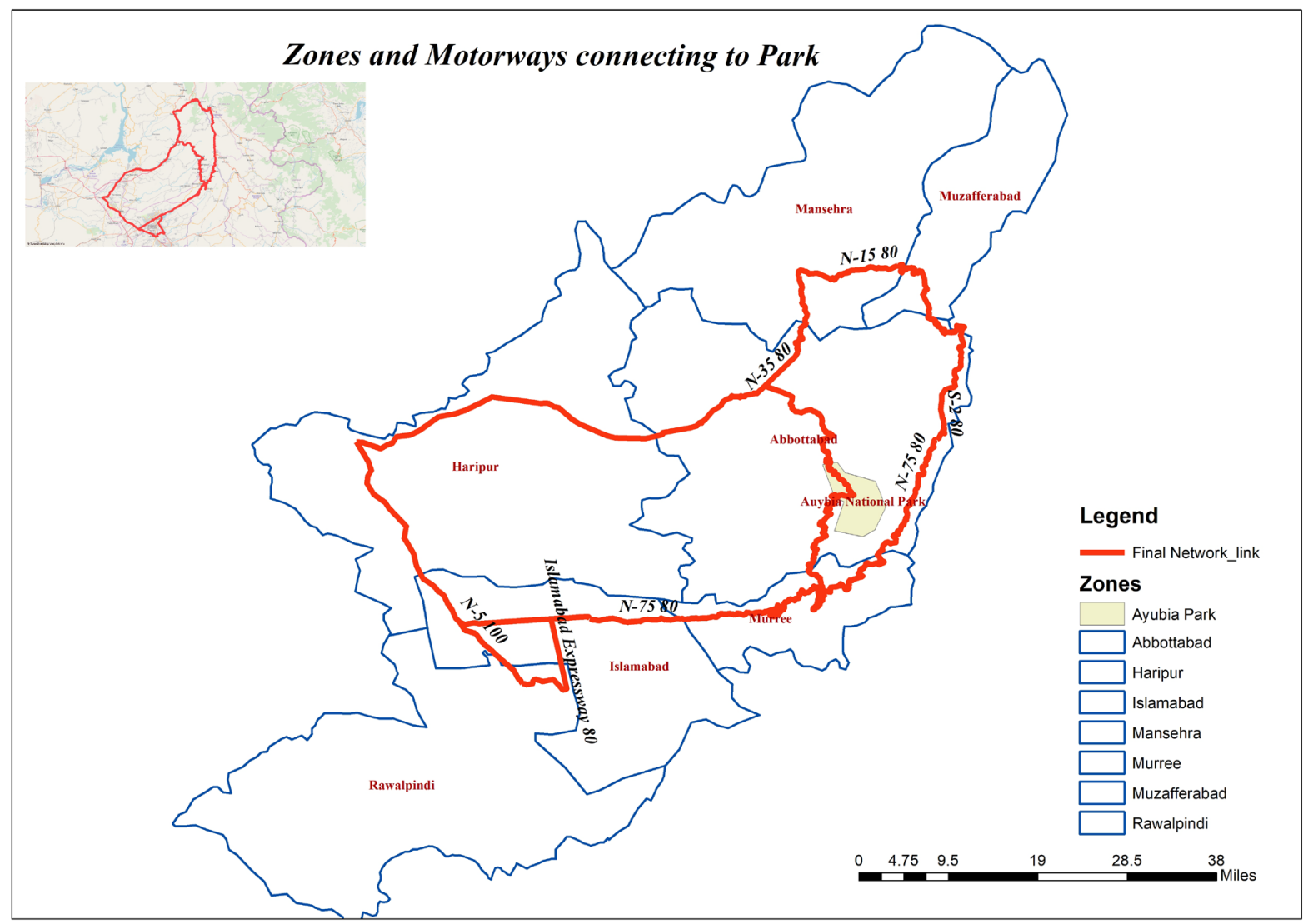

Figure 3. The case study map showing the important zones included and also the network for traffic assignment.

Table 1. Characteristics of the selected network.

\begin{tabular}{cccc}
\hline Name of the Links & Max. Speed in kilometers & Capacity & Number of Lanes \\
\hline N-75 & 80 & 8000 & 4 \\
Abbottabad Road & 50 & 3000 & 2 \\
N-35 & 80 & 8000 & 4 \\
N-5 & 100 & 8000 & 4 \\
Muzaffarabad Road & 50 & 3000 & 2 \\
Islamabad Expressway & 80 & 12,000 & 6 \\
S-2 & 80 & 3000 & 2 \\
N-15 & 80 & 3000 & 2 \\
\hline
\end{tabular}

(Source: National Highway Authority (NHA, Pakistan)

selected zones were extracted from the available data. The traffic count presented in Table 2 is peak hour data regardless of the purpose to the destination, as peak hour volume is a mixture of traffic generated by the locals and visitors.

The next step is the descriptive analysis and deduction of alternative strategies based on the online questionnaire. By the execution of instinct changes in traffic input, based on the response collected from the tourists, possible outcomes are analyzed in detail in Section 4.2.1. 
Table 2. Origin to destination matrix for the selected traffic analysis zones (Year, 2019).

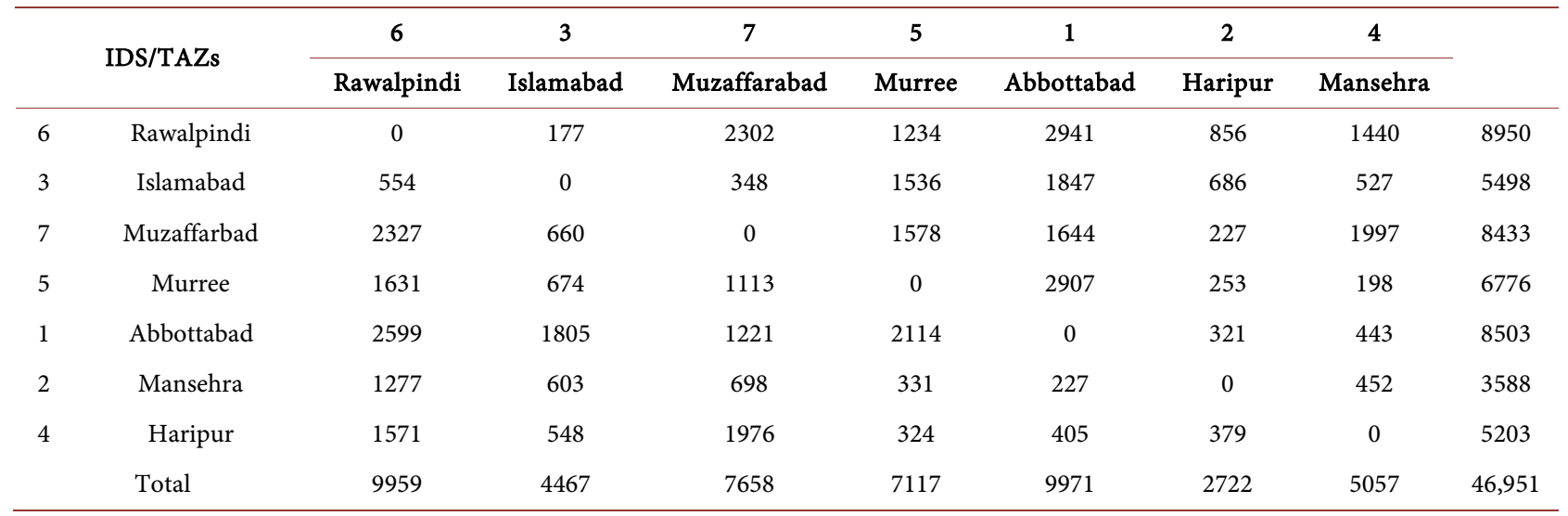

Source: National Transport Research Centre (NTRC), Pakistan.

\section{Data Analysis}

\subsection{Descriptive Analysis}

The identification and gathering of relevant information (to extrapolate the research parameters) is itself a fundamental element of successful research. The respondents were asked to express their opinion regarding the implementation of certain policies to avoid congestion in the near future. Out of 176 respondents, 84 (47.73\%) respondents were male, and 92 (52.27\%) females. A few characteristics are mentioned in detail in Table 3 . The respondents agreed with the fact that most of the time the congestion is due to defective vehicles. They were also asked if they would support the ban on such vehicles that don't have a maintenance certificate; 109 (63\%) respondents stated "yes," and only 67 (38\%) of the respondents opposed the ban on such type of vehicles. Similarly, $63.60 \%$ of the respondents were in favour of the additional toll imposed on the visitors during the peak hours. Similarly, 133 (75.57\%) of the respondents were in favour time-of-day based access restrictions for heavy vehicles; only $24.43 \%$ opposed this strategy. The management of the protected areas comprises of planning and consolidation of mobility strategies. An elegant mobility network enhances the visitors' experiences through guidance, by ensuring time-saving, safety, and by the provision of detailed information about the route [25]. Concerning all other proposed strategies, the respondents were found less interested as compared to the aforementioned ones.

\subsection{Network Analysis (Based on Preferred Strategies)}

The next step after the preparation of all the relevant data and identification of possible measured as preferred by the respondents is the traffic assignment and also the adjustment of the V/C ratio to improve the travel free flow. The analysis part is divided into three parts.

1) The first part is about the restriction on the vehicles which don't have a vehicle inspection and maintenance certificate. There is no periodic fitness inspection for privately owned passenger vehicles and motorcycles. The issue of vehicle 
Table 3. Sociodemographic characteristics of respondents and response regarding various strategies.

\begin{tabular}{|c|c|c|c|c|c|c|c|}
\hline Trip Characteristics & Levels & Frequency & Percent & Trip Characteristics & Levels & Frequency & Percent \\
\hline \multirow{5}{*}{ Mode of transport } & Private Car & 86 & 48.86 & \multirow{2}{*}{ Gender } & Male & 84 & 47.73 \\
\hline & Public Transport & 43 & 24.43 & & Female & 92 & 52.27 \\
\hline & Taxi & 9 & 5.11 & \multirow{3}{*}{ Education } & Undergraduate & 75 & 42.61 \\
\hline & Motor Bike & 29 & 16.48 & & Graduate & 37 & 21.02 \\
\hline & Walking & 9 & 5.11 & & Masters & 63 & 35.80 \\
\hline \multirow{2}{*}{ Congestion } & Yes & 119 & 67.61 & & Doctorate & 1 & 0.57 \\
\hline & No & 57 & 32.39 & \multirow{2}{*}{$\begin{array}{l}\text { Ban on vehicles having no } \\
\text { maintenance certificate }\end{array}$} & Yes & 109 & 61.94 \\
\hline \multirow{2}{*}{$\begin{array}{l}\text { Congestion due to } \\
\text { defective vehicles }\end{array}$} & Yes & 121 & 68.75 & & No & 67 & 38.06 \\
\hline & No & 55 & 31.25 & \multirow{2}{*}{ Toll charges implementation } & Yes & 112 & 63.60 \\
\hline \multirow{2}{*}{$\begin{array}{l}\text { Availability of Parking } \\
\text { space }\end{array}$} & Yes & 130 & 73.86 & & No & 64 & 36.34 \\
\hline & No & 46 & 26.14 & \multirow{3}{*}{ Age } & $18-24$ & 96 & 54.45 \\
\hline \multirow{2}{*}{$\begin{array}{l}\text { Time-of-day based } \\
\text { access restrictions for } \\
\text { the heavy vehicle }\end{array}$} & Yes & 133 & 75.57 & & $25-30$ & 27 & 15.34 \\
\hline & No & 43 & 24.43 & & More than 30 & 53 & 30.11 \\
\hline
\end{tabular}

safety and fitness remains a huge concern in the case of Pakistan because there is no federal-level agency supervising or monitoring the issues of vehicle safety. $74 \%$ of the accidents in the capital region had at least one vehicle with fitness and loading related safety issues that contributed to the accident and its consequences [26]. For this purpose, assumptions are made based on statistics obtained by the concerned officials of the National Highway Authority of Pakistan.

a) It is assumed that $7.5 \%$ of the total vehicles have no certificate for the last 10 years

b) Another assumption was made that vehicles having no inspection certificate for the last 5 years are $15 \%$ of the total volume

c) Vehicles having no inspection certificate for the last 3 years, are up to or more than $25 \%$ of the total volume

2) The second strategy is the implementation of a toll on certain links; links with a high usage from the visitors and geographical proximity to the national park. The purpose of the toll is to discourage the users from using these links.

3) The third part is devising a strategy for the implementation of time-of-day based access restrictions for the heavy vehicle.

\subsubsection{User Equilibrium Traffic Assignment}

The Ayubia national park is located between zone Murree and Zone Abbottabad. Tourist mostly comes from Rawalpindi, Islamabad, Muzaffarabad and also from Mansehra. The inflow of the tourist not causes the congestion on Abbottabad road but also disrupts the normal traffic on connecting roads like S-2 connecting Murree with Muzaffarabad, and N-75 connecting the Islamabad to Murree. During the peak hours, the volume to capacity ratio exceeds up to 1.7. Length of the links, maximum allowed speed, the capacity of the link, number of lanes, travel free flow is the relevant attributes associated with the links see Figure 4. 


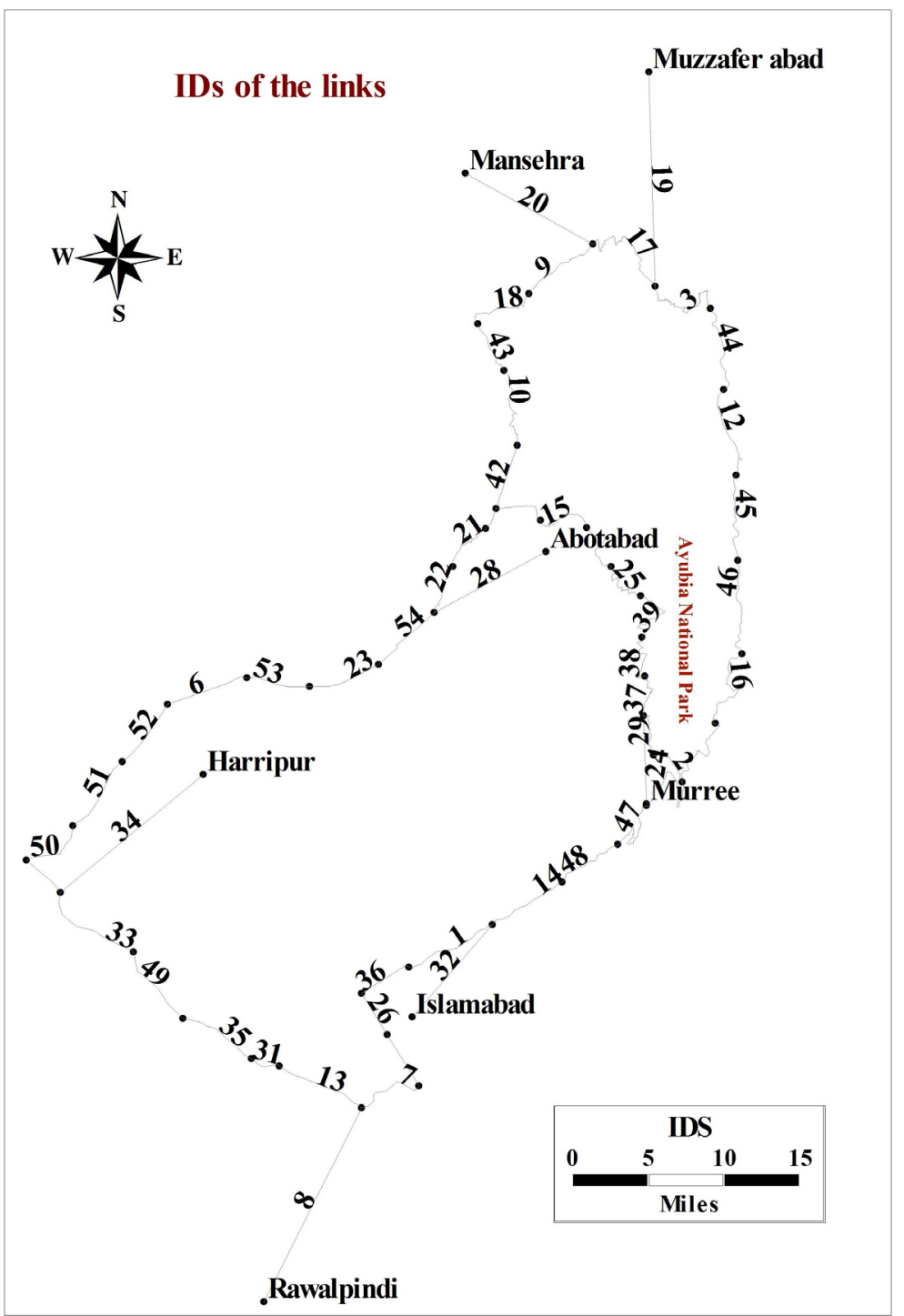

Figure 4. IDs Assigned to the links and maximum allowed speed on network links.

The trans cad software was used to generate traffic assignment. The OD matrix shown in Table 2 represents the volume of peak hours from ADT.

The method used for the traffic assignment was the user equilibrium method. User Equilibrium uses an iterative process to achieve a convergent solution, in which no travelers can improve their travel times by shifting routes. In each iteration, Trans CAD computes network link flows, which incorporate link capacity restraint effects and flow-dependent travel times. Single class traffic assignment has opted from the assignment types. The Bureau of public roads (BPR) was used as the delay function. Other parameters were traveling free flow, Alpha $=0.15$, Beta $=4.00$, and the capacity of the links. Almost 50 iterations, the software generates the results of the traffic assignment based on the input flow given in the form of the OD matrix. It can be clearly seen in Figure 5 . The volume to the capacity ratio on-road named as S-2 lies between $1.50-1.70$. Similarly, the $\mathrm{V} / \mathrm{C}$ ratio on $\mathrm{N}-15$ and partially on the Abbottabad road is also higher than 1.1. 


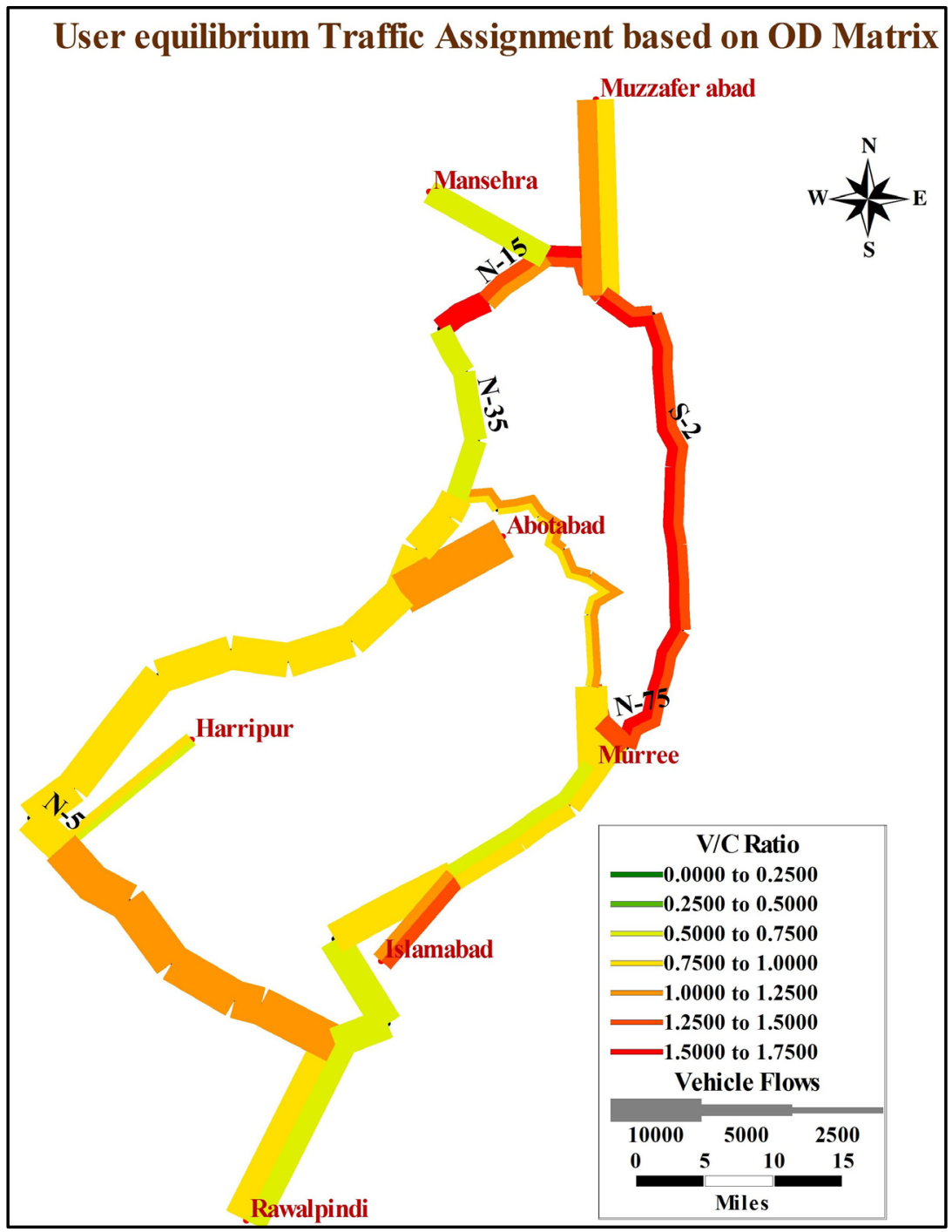

Figure 5. User Equilibrium assignment based on projected volume for peak hour.

The $\mathrm{V} / \mathrm{C}$ ratio at certain points exceeds up to 1.70 . The graphical representation of $\mathrm{V} / \mathrm{C}$ ratio as per individual links is shown in Figure 6.

At almost two of the smaller links, the V/C ratio is more than 1.6. For example, for link 17 , the $\mathrm{AB}$ ratio is 1.61 , and the $\mathrm{BA}$ ratio is 1.45 , respectively. It can also be viewed in Figure 6 that $\mathrm{V} / \mathrm{C}$ ratio continues to vary from the lowest of 0.5 to 1.7. The traffic generated from the zone, Rawalpindi towards Muzaffarabad, passes through the N-75 and S-2. If only the traffic coming from these two zones switch to alternative routes, i.e., N-5, N-35, N-15 instead of N-75 and S-2, $\mathrm{V} / \mathrm{C}$ ratio would be minimized. But the only problem is that an alternative route is a bit longer in terms of distance.

\subsubsection{Analyzing the Impact of Restrictions on Vehicles without an Inspection Certificate}

The maintenance level of every two out of 10 cars is not that good. There are vehicles and also heavy trucks with low-quality engines having no vehicles inspection 


\section{Graphical Representation of V/C Ratio}

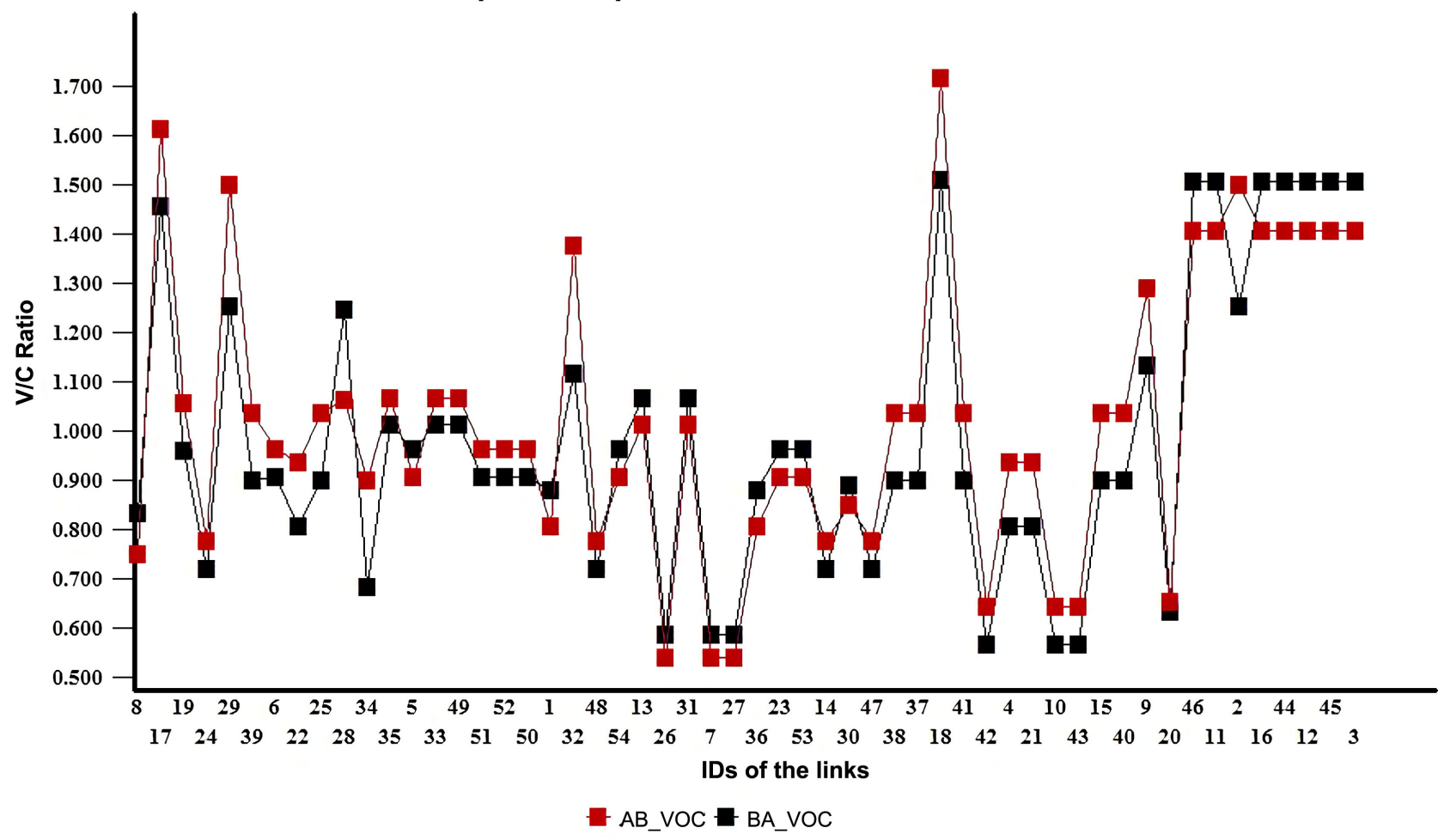

Figure 6. Volume to the capacity ratio for the user equilibrium traffic assignment.

certificate [26]. There are reasons why there should be a ban on these vehicles, 1) Vehicle without inspection is not favorable for environment-friendly traffic flow, 2) driving behavior of drivers of these vehicles is vulnerable it can cause accidents to other vehicles, and 3) Abrupt disruption inflow of the vehicles cause serious effects for through traffic i.e., accidents, reduces flow, reduces capacity. An assumption was made about the total volume of these kinds of vehicles. It was assumed that the vehicles having no inspection certificate for the last ten years, five years, and three years are around $7.5 \%, 15 \%$, and $25 \%$, respectively. It can be clearly seen from Figures 7-9, that if the restrictions are imposed on those vehicles who do not have obtained the vehicle inspection certificate for the last ten years, five years and three years. There is a slight improvement in the $\mathrm{V} / \mathrm{C}$ ratio at all these three levels of assumptions.

It is not obvious that there is a certain amount of vehicles, but it is worth mentioning here that the ban on these kinds of vehicles can bring a certain change.

The graphical representations in Figures 10-12 show that previously this ratio was up-to 1.70 and with the ban on $7.5 \%$ of these vehicles it declines to 1.5 , and if the authorities got successful in imposing the ban on vehicles having no certificate for last 5 years those are equal to $15 \%$ the $\mathrm{V} / \mathrm{C}$ ratio declines to 1.3 . And lastly, by making sure that there is no such vehicle, in this case, study area, which means banning the $25 \%$ of vehicles having no certificate for last three years it can drop down the V/C ratio under 1.0 and only for few small links it is up to 


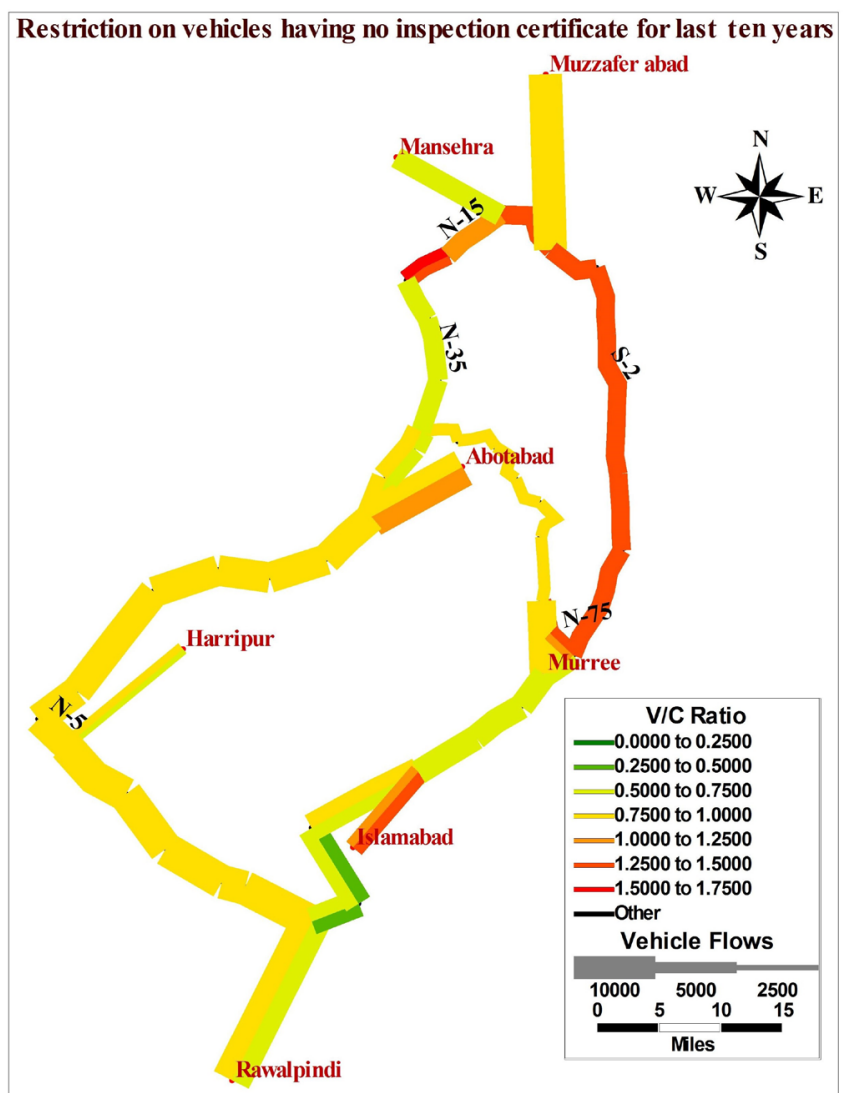

Figure 7. Restriction on using the vehicles having no inspections certificate for last 10 years.

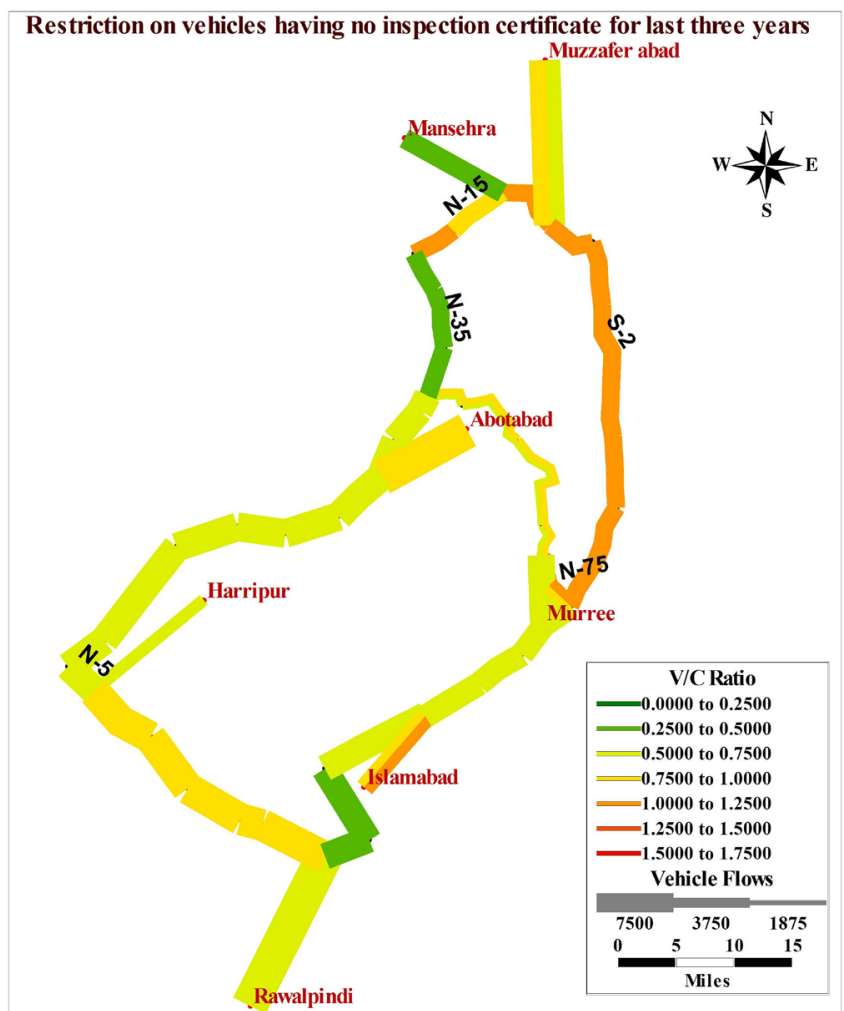

Figure 8. Restriction on using the vehicles having no inspections certificate for last 3 years. 


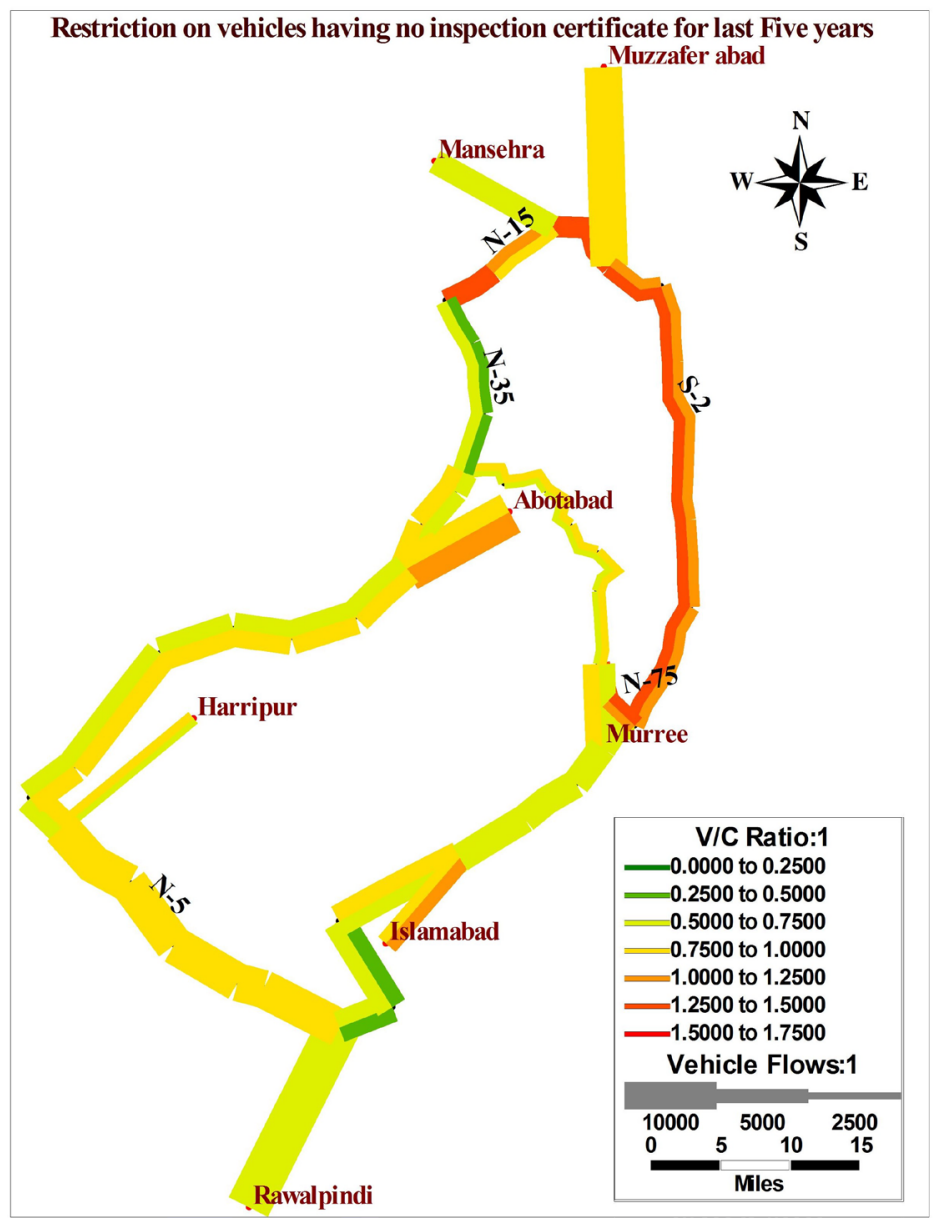

Figure 9. Restriction on using the vehicles having no inspections certificate for last 5 years.

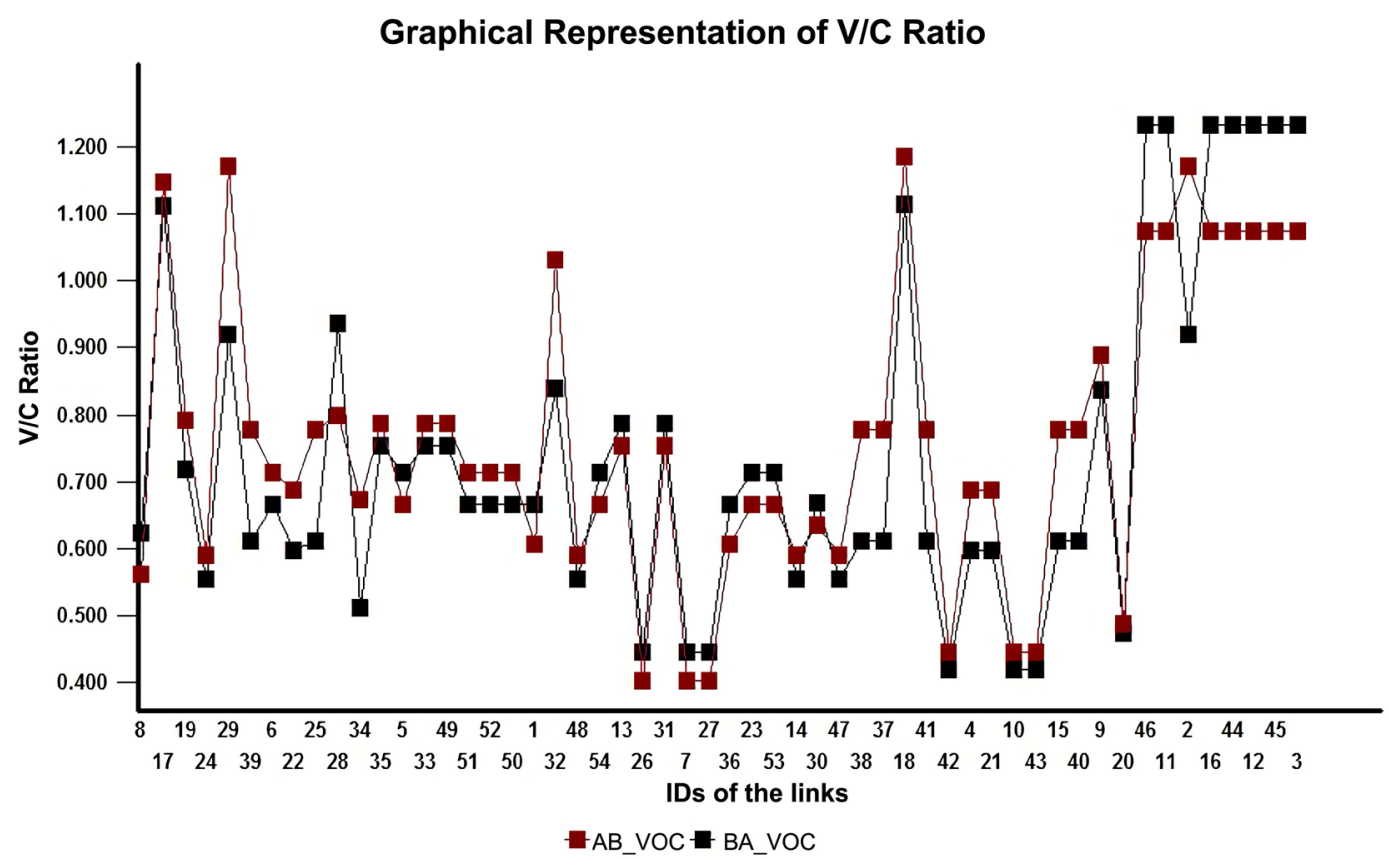

Figure 10. Graphical representation of impact on V/C ratio on all the links by the ban of vehicles having no inspection certificate for last 3 years. 


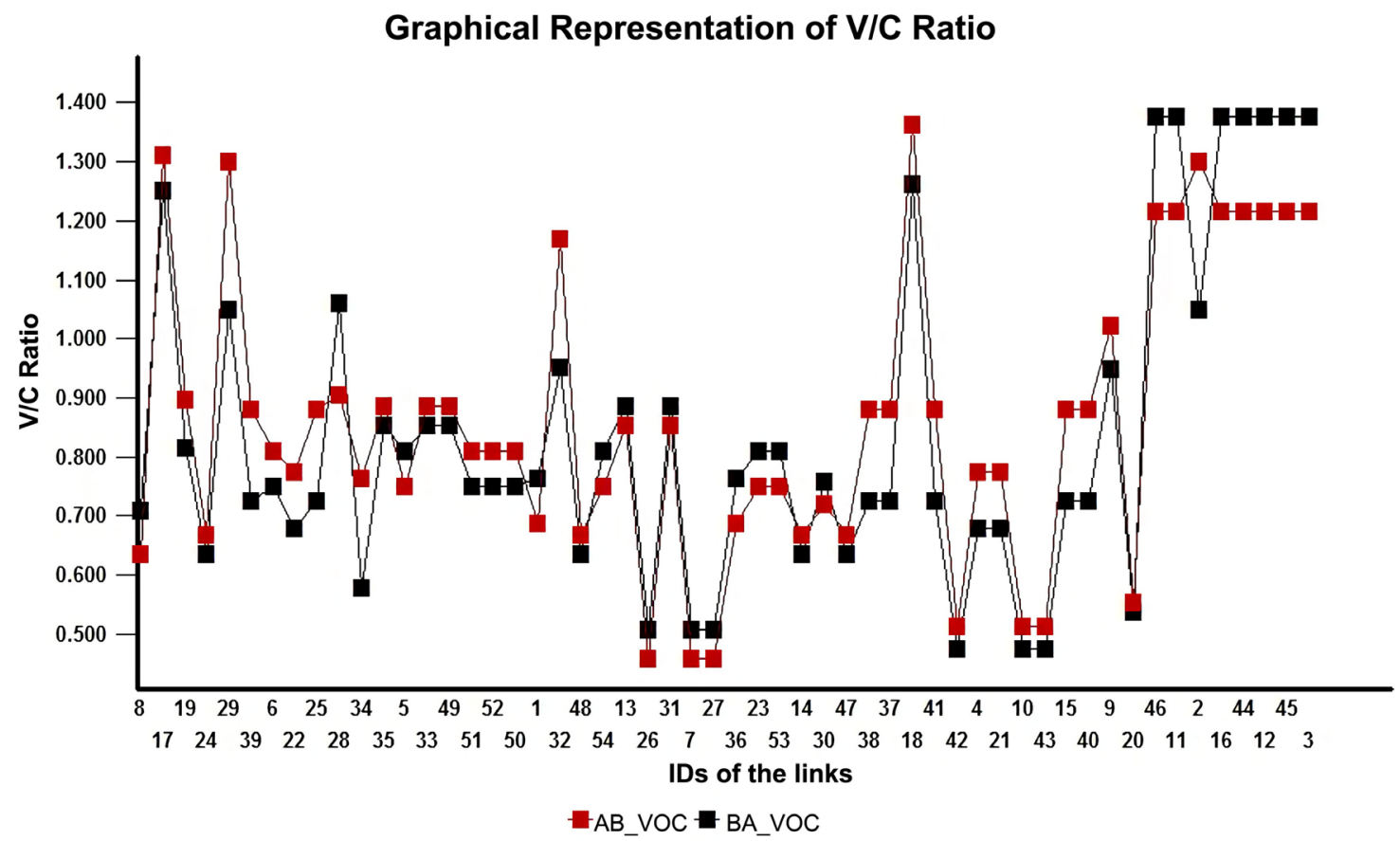

Figure 11. Graphical representation of impact on V/C ratio on all the links by the ban of vehicles having no inspection certificate for last 5 years.

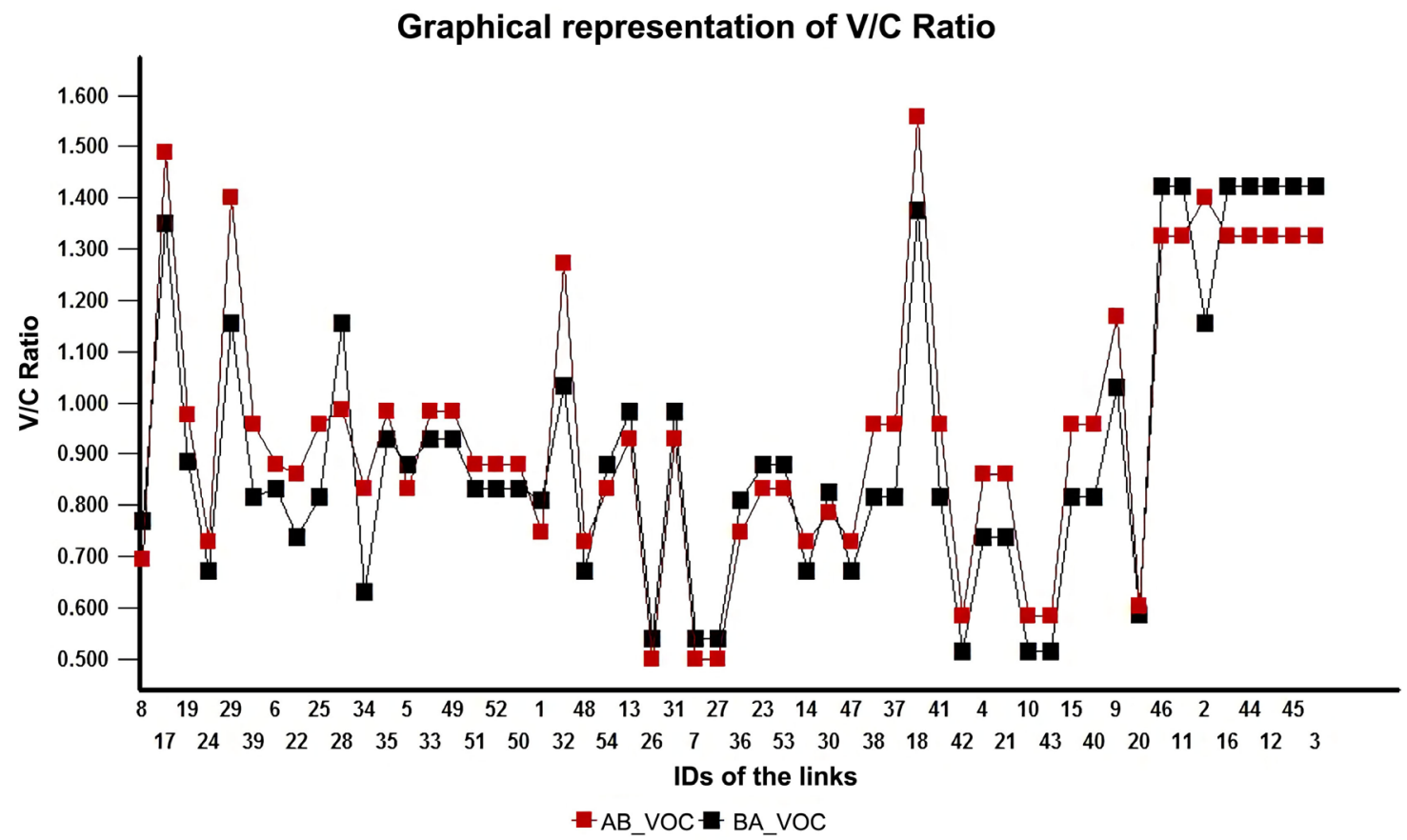

Figure 12. Graphical representation of impact on V/C ratio on all the links by the ban of vehicles having no inspection certificate for last 10 years.

1.2. The ban on such vehicles can be a temporary solution. However, it can be further combined with low emission zones, if required.

The next part of the analysis on carried out on understanding what would be the effect of implying toll on the specific location. 


\subsubsection{Implementation of Toll during Peak Hours on Certain Roads}

At the public level, toll implementation is never easily accepted by the major community. To further analyse, if the toll could help to solve this problem, the analysis was performed. Transcad usually consider link cost in terms of time units to perform equilibrium assignment and therefore, VoT (Rs/hr) is used to convert toll (Rs) into time units. This represents an additional time added to the travel time of the link. The average value of time as predicted in [27] is 500 $\mathrm{pkr} / \mathrm{hr}=3.25 \$ / \mathrm{hr}$ for the year 2020. Rs. 1000 (i\$) considered as the minimum toll on specified links. We performed analysis using different toll values as well, however, results were not meaningful. These links are selected based on the high usage from visitors, geographical proximity to the national park and also a V/C ratio exceeding 1.1 in peak hour. These links are, for example, at link 7, link 2, link 41, and link 44, i.e., Rawalpindi towards Islamabad, N-75 towards Abbottabad Road, Muzaffarabad to Murree and $\mathrm{N}=35$ towards Abbottabad. All the links are highlighted with the red circle in Figure 13. It is worth mentioning

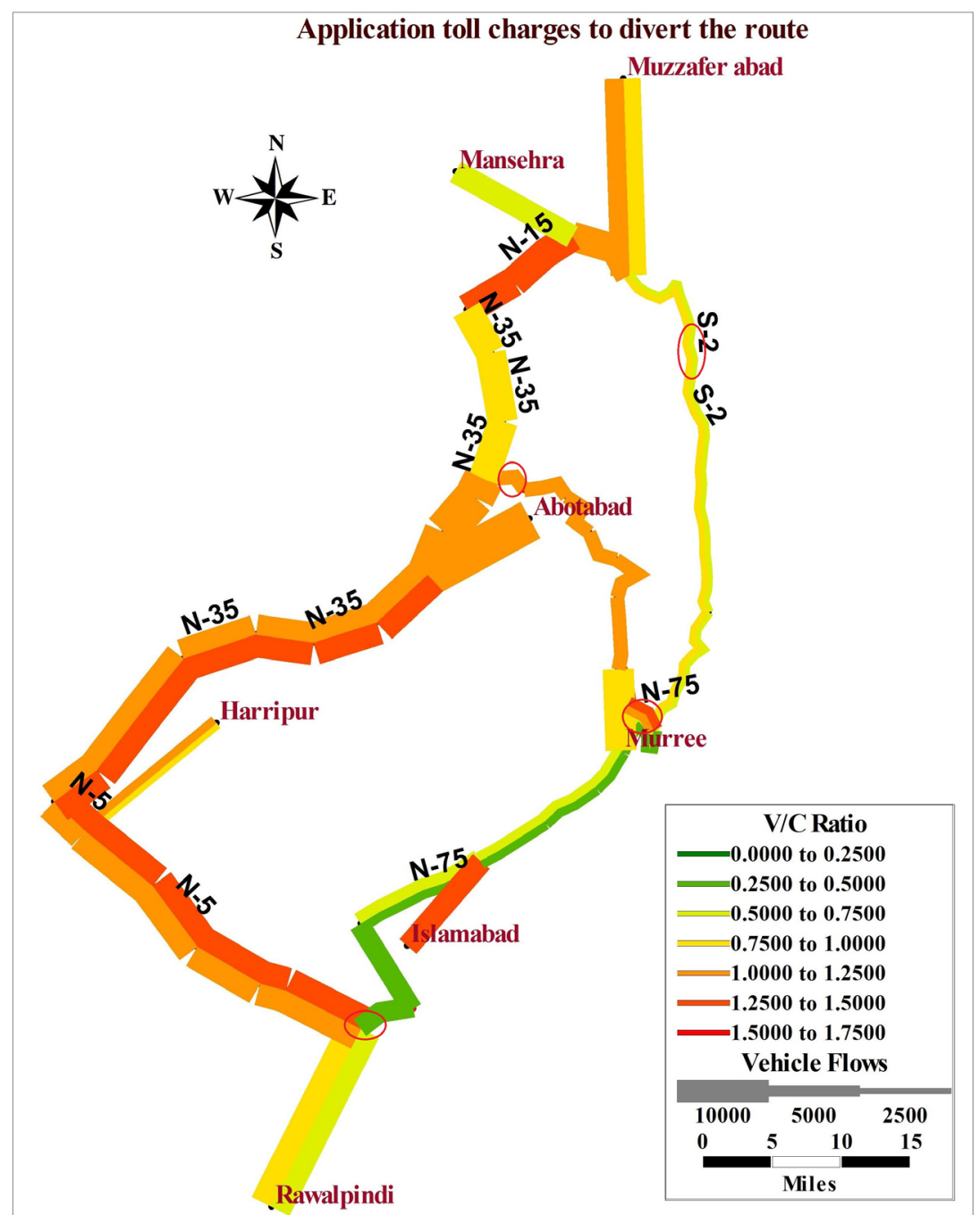

Figure 13. Application of Toll charges on certain entry points to divert the traffic to alternative routes. 
here that the toll also has an impact on the $\mathrm{V} / \mathrm{C}$ ratio. It can be clearly seen in Figure 13 and Figure 14. With the implementation of toll charges on said links, there is an effective decline in the volume of capacity ratio from 1.7 to lower than 1.30. However, it has increased the volume on N-5, N-35, and also on N-15. But if the situation is compared with the current situation, it is far better than the previous situation. The application of toll is indeed a good idea but need to keep in mind the public interest.

\subsubsection{Time-of-Day Based Access Restriction for Heavy Vehicles} (Trucks etc.)

Another issue that is of serious concern is the combined movement of heavy traffic (trucks and buses) along with light vehicles. According to data collected by the NTRC, it was noticed that $14.16 \%$ of the total volume is heavy vehicles. The time of the day based restrictions to the heavy vehicles are considered as the optimal solution. The heavy vehicles will be restricted on these connecting roads for peak hours and will only be allowed pass by in permissible time windows. For this purpose, it is suggested to create time windows for heavy vehicles. The suggested time windows are classified into two slots, e.g., 10:00PM to 06:00AM, and the second slot is 10:00AM to 02:00PM. The results are shown in Figure 15 and Figure 16.

If the concept of permitted and prohibited access for heavy vehicles is applied, it can decrease the traffic volume up to almost $14.16 \%$ in peak hours. Analysis indicates that this strategy can be vital as it reduces the volume to the capacity ratio from 1.7 to 1.4 during the peak hours. But still, some of the links have V/C ratio of more than 1.3 which is not favourable. The results of this scenario

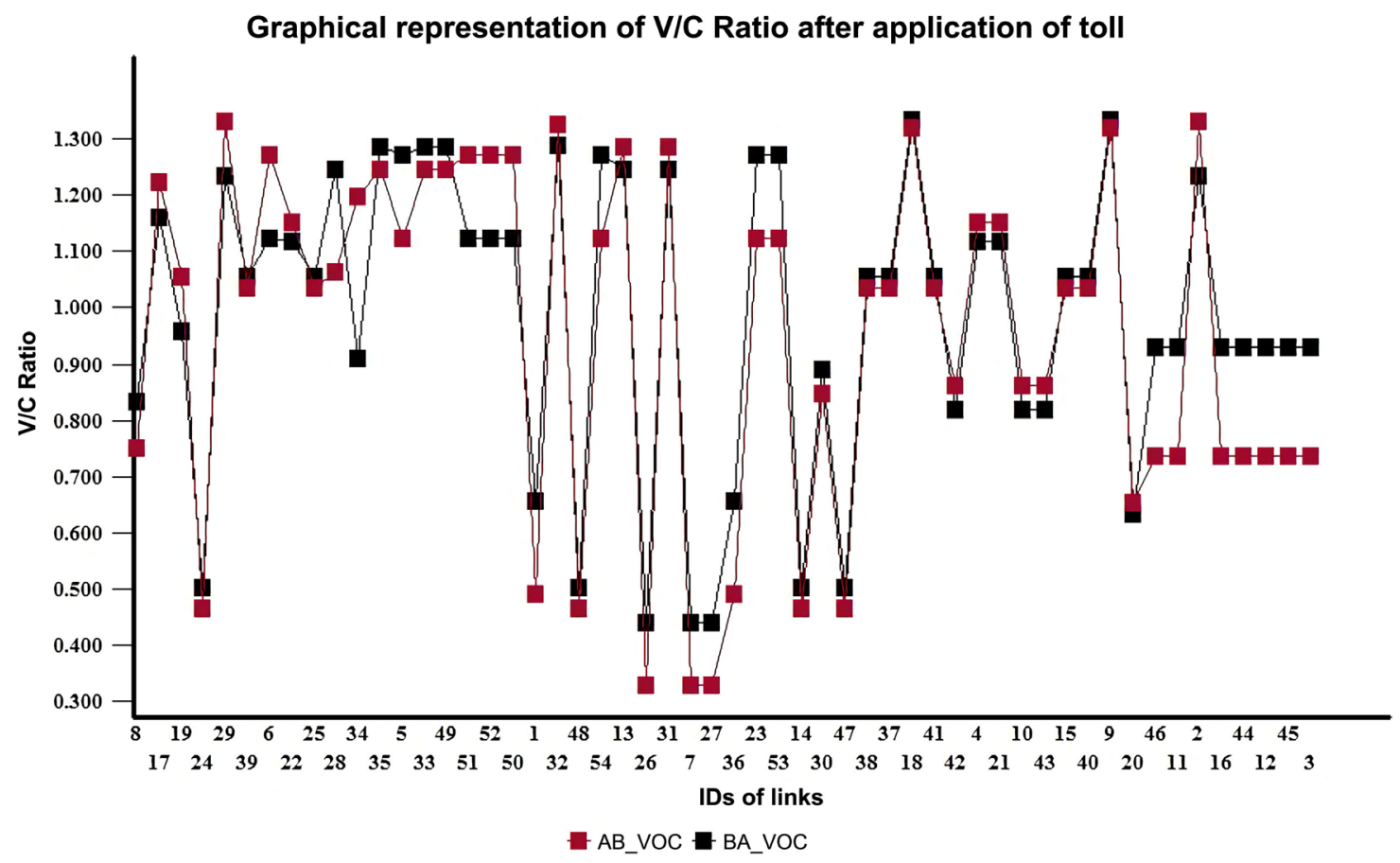

Figure 14. Graphical representation of impact on V/C ratio on all the links by application of toll charges. 


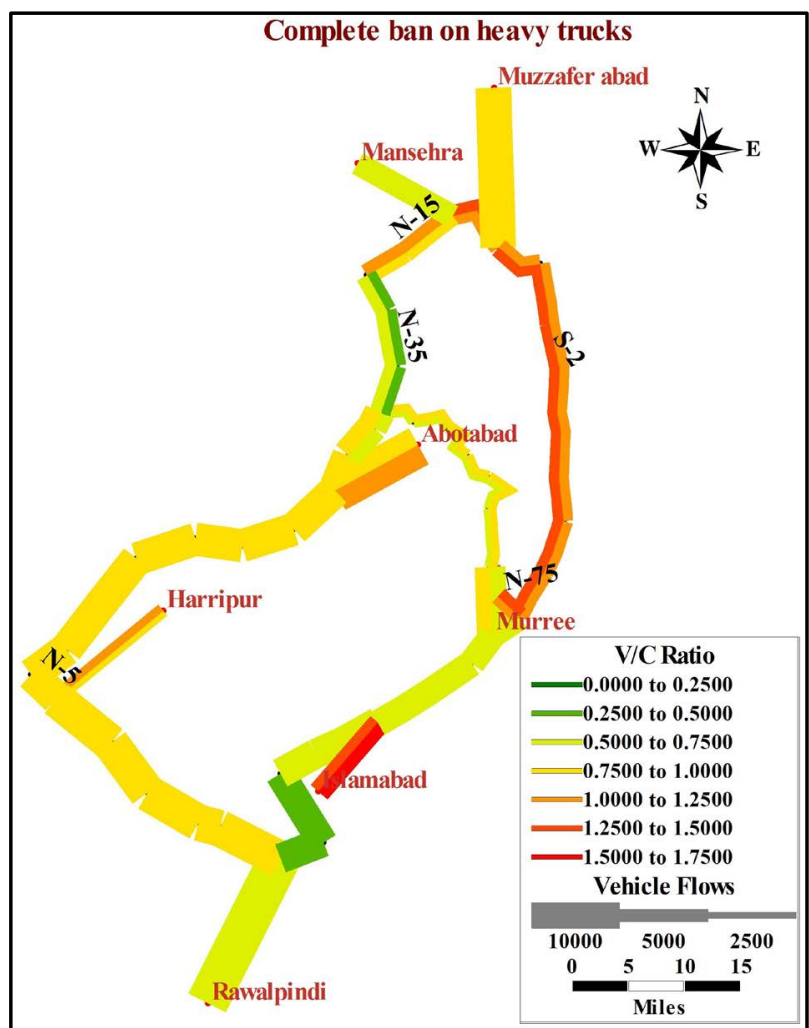

Figure 15. Impact of creating permitted and prohibited time windows for heavy vehicles on $\mathrm{V} / \mathrm{C}$ ratio.

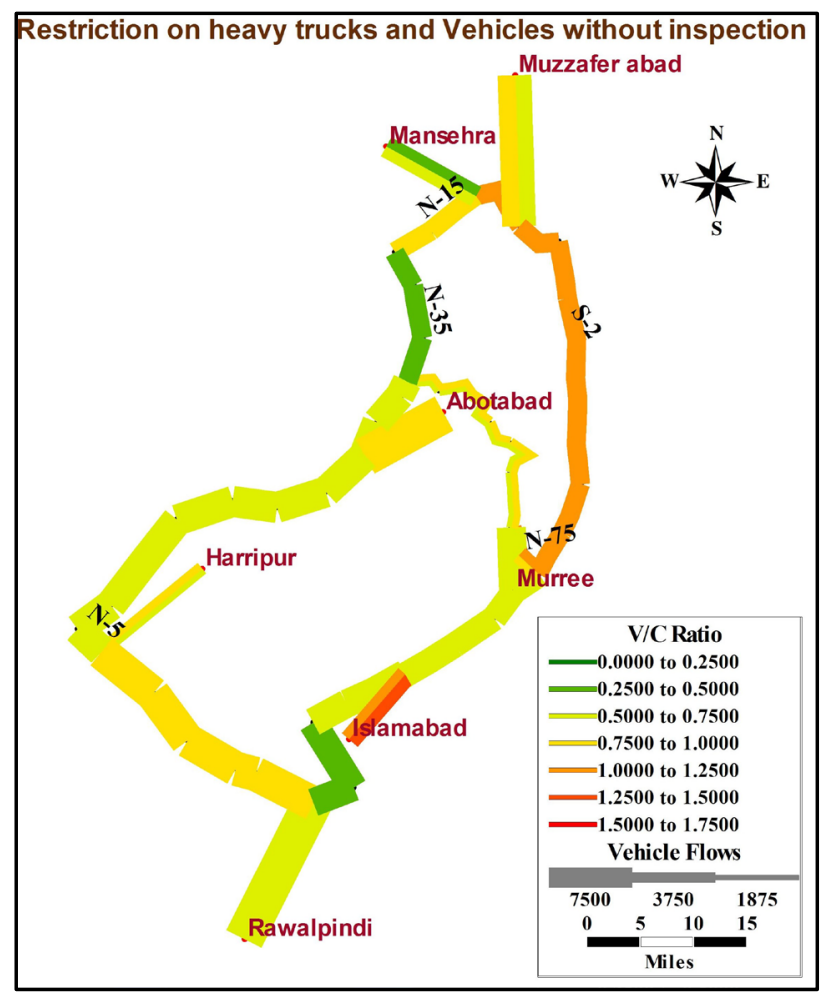

Figure 16. Impact of time windows along with ban on vehicles having no inspection certificate for last 10 years on $\mathrm{V} / \mathrm{C}$ ratio. 
have more favourable results as compare to all other scenarios analysed previously (see Figure 17 and Figure 18). As the V/C ratio is almost less than 1.1, only for a few of the links it is more than 1.1, but still, it is less than 1.2.

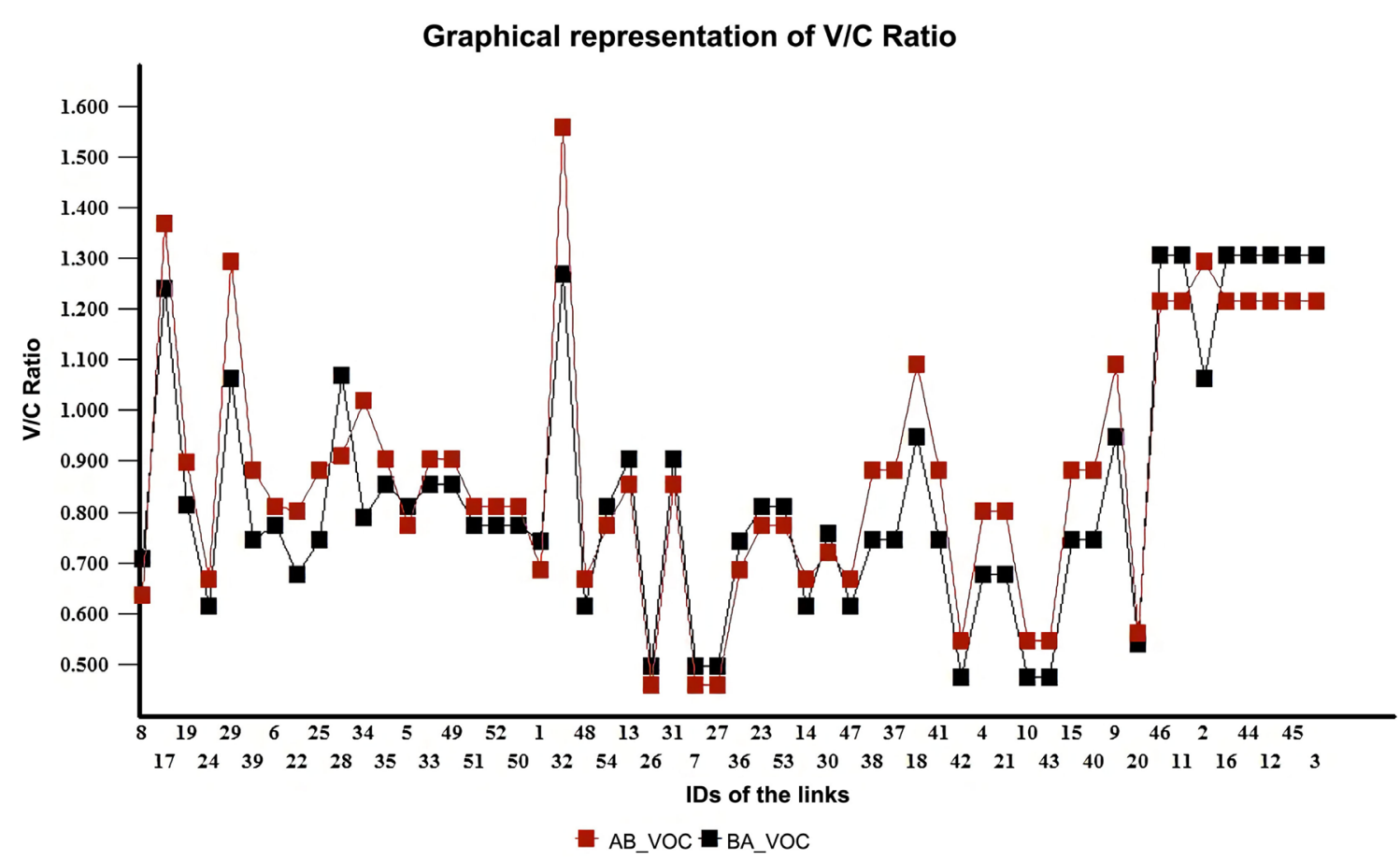

Figure 17. Graphical representation of impact on V/C ratio by the implementation of permitted and prohibited time windows for heavy vehicles.

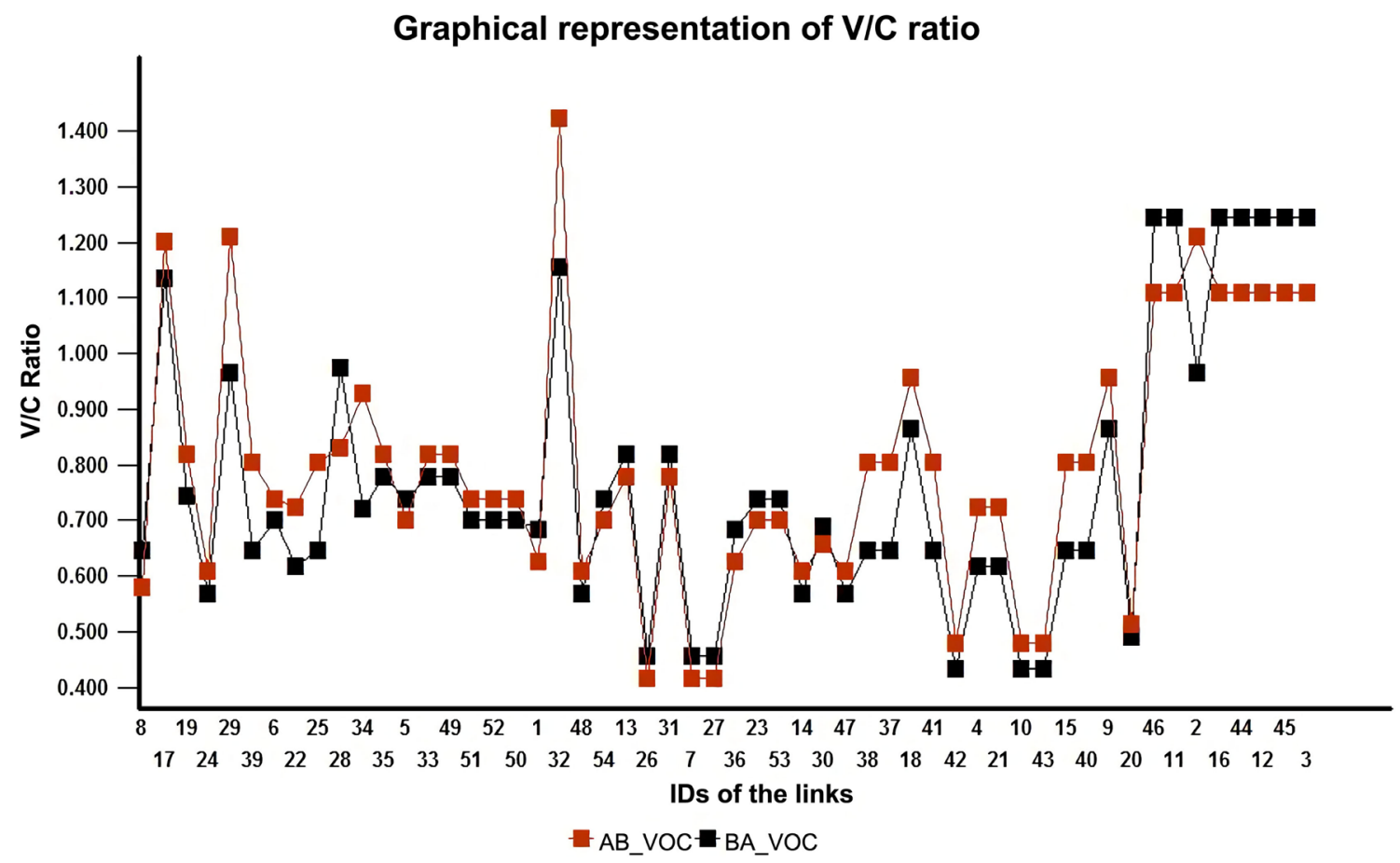

Figure 18. Graphical representation of impact on V/C ratio by the implementation of permitted and prohibited time windows for heavy vehicles along with ban on vehicles without inspection. 
All three different strategies have varying results and have a direct impact on the volume to capacity ratio of certain links. These results were presented to the experts involved in various planning departments, and their response was analyzed to determine the impact of these strategies on tourism. The experts' opinion is further discussed in detail as under.

\subsection{Experts Opinion}

The inspiration for the experts' opinions was carried out from the concept of Delphi method. A Delphi study is a widely used method to obtain input from a group of experts. Although initially developed to predict cold war enemy attack probabilities, the technique has been widely used across numerous disciplines as a method to seek expert opinion in an iterative structured manner. The key features of the method are anonymity between participants with controlled feedback provided in a structured way [28]. However, this research only contains experts' opinions rather than an iterative process. The results of the analysis carried out in Section 4.2.1 were presented to the experts, and their response was recorded using the questionnaire method. Experts from five departments related to transport and tourism participated in the Delphi survey. The concerned departments are the National Highway Authority (NHA), the National Transport Research Center (NTRC), the Pakistan Tourism Development Corporation (PTDC), Galiyat Development Authority (GDA), and the Planning Commission (tourism section). The questionnaire was divided into two parts; the first part was the identification of the impact of the implementation of multiple strategies to attract the number of tourists and to improve the transport network. This part included questions such as: would there be an increase in the number of visitors because of this particular strategy? Will these traffic network strategies improve the traffic movement? The second part was about the impact of the implementation of these scenarios on the local population. This section contained questions such as: would this particular strategy increase the quality of life and living standard? Would these strategies attract more investment? A total of 15 experts shared their opinion; the number of experts participated from different departments is as under: NHA (4), NTRC (4), PTDC (2), GDA (2), Planning Commission (3).

The experts inquired about a few of the vital characteristics e.g., the volume of visitors, traffic flow, visitors experience, fuel consumption, average trip cost, degradation of natural loss and accessibility factor [29] [30] [31]. It can be observed in Table 4. That 10/15 respondents agreed that a ban on vehicles without certificate will increase the amount of tourists. Similarly, 14/15 of the experts agreed that heavy vehicle access restriction will definitely improve the visitors experience in a way that there will be lesser delays. Almost 9/15 (60\%) of the experts stated that a toll application may discourage the number of tourists. There are also some objections from the experts, for example, almost 7/15 (47\%) of the experts didn't agree that a sustained flow can be achieved by the restriction on 
Table 4. Response collected from the experts (impact of various strategies towards the increase in tourism).

\begin{tabular}{|c|c|c|c|c|c|c|}
\hline \multirow[b]{2}{*}{ Visitors perspective } & \multicolumn{2}{|c|}{$\begin{array}{l}\text { Impact on tourism from } \\
\text { restrictions on vehicles without } \\
\text { an inspection certificate }\end{array}$} & \multicolumn{2}{|c|}{$\begin{array}{l}\text { Impact on transport } \\
\text { and tourism from a toll } \\
\text { during peak hours }\end{array}$} & \multicolumn{2}{|c|}{$\begin{array}{l}\text { Impact on transport and } \\
\text { tourism from the creation of a } \\
\text { time window (permitted and } \\
\text { prohibited) for heavy vehicles }\end{array}$} \\
\hline & $\begin{array}{l}\text { Yes } \\
(\%)\end{array}$ & $\begin{array}{l}\text { No } \\
\text { (\%) }\end{array}$ & $\begin{array}{l}\text { Yes } \\
(\%)\end{array}$ & $\begin{array}{l}\text { No } \\
\text { (\%) }\end{array}$ & $\begin{array}{l}\text { Yes } \\
(\%)\end{array}$ & $\begin{array}{l}\text { No } \\
\text { (\%) }\end{array}$ \\
\hline Increase in the number of visitors & 67 & 33 & 40 & 60 & 93 & 7 \\
\hline Quality of transport services and infrastructures & 87 & 13 & 73 & 27 & 80 & 20 \\
\hline Sustained traffic flow & 53 & 47 & 67 & 33 & 53 & 47 \\
\hline Enhanced vision for vistas (sightseeing) & 67 & 33 & 73 & 27 & 87 & 13 \\
\hline Reduction in Fuel consumption and Emission level & 93 & 7 & 73 & 27 & 60 & 40 \\
\hline Degradation of natural loss & 67 & 33 & 60 & 40 & 40 & 60 \\
\hline Reduction in the average cost of the trip & 67 & 33 & 27 & 73 & 27 & 73 \\
\hline Enhanced visitor mobility & 73 & 27 & 60 & 40 & 80 & 20 \\
\hline Stress/mental pressure reduction & 87 & 13 & 47 & 53 & 67 & 33 \\
\hline Reduced vulnerability & 93 & 7 & 40 & 60 & 87 & 13 \\
\hline Increased accessibility & 53 & 47 & 47 & 53 & 67 & 33 \\
\hline Increased comfort and safety & 73 & 27 & 67 & 33 & 60 & 40 \\
\hline
\end{tabular}

vehicles without a maintenance certificate, and the same was the case for the response towards the measure of time. Almost 7/15 and 8/15 of the experts also denied the fact that the action of the ban on vehicles and toll applications would improve accessibility; however, 10/15 (67\%) of the experts agreed that heavy vehicle access restriction would increase the accessibility towards the national park see Table 4.

The locals' response towards the policy implementation is considered to be of significant importance. The experts were asked about various aspects concerning locals. The response collected from the experts shows that 10/15 (67\%) respondents agreed that the ban on vehicles and heavy vehicles access restrictions would improve the quality of life of the locals. It will attract more tourists towards the national park, as the visitors' experience will improve, and the quality of the trip will increase the ranking of a destination. Out of 15 respondents, 11 respondents didn't agree that the ban on vehicles without a certificate will create additional income for the government. As to restrict these vehicles, the government has to invest a lot in enforcement. However, 10/15 (67\%) of the experts agreed that business opportunities for locals would improve with the implementation of a ban on vehicles and heavy vehicle restriction, as there will be an increase in the tourism sector. Around $80 \%$ of the experts agreed that the time-based access restriction to heavy vehicles will generate the revenue for the locals. Only $20 \%$ of the respondents were against the fact. The experts were asked if there would be improvement in roads condition and public infrastructure by the implementation of aforementioned strategies. The experts response 
was interesting, as $87 \%$ of the experts stated that restriction on vehicles without an inspection certificate would improve the roads condition and public infrastructure. Similarly, $67 \%$ of the experts stated that application of toll charges during peak hours will have a positive effect on road conditions. However, only $27 \%$ of the experts agreed that time based access restriction would improve the roads condition that and $73 \%$ of the respondents denied this aspect. The percentage of the response of the experts towards all other variables from the locals' perspective can be seen in Figure 19.

\section{Discussion}

In the questionnaire-based response, the respondents favored the implementation of the following strategies: implementation of toll on certain links, ban on vehicles having no inspection certificate, and time-of-day based access restriction for heavy vehicles. Therefore, these 3 strategies were applied on secondary data. The results obtained would imply a step towards improvements. The roads with lower capacity pass through the mountains, and it is not an economical approach to increase the capacity by increasing the number of lanes. However, other problems like the ban on vehicles without maintenance certificates can decrease the tourists' volume of roads. Delays, capacity reduction, accidents, less free flow, less travel time are the other problems that are also associated because of these vehicles. If the problem can be solved by the ban on these kinds of vehicles, it is of worth to impose this strategy as it is in the interest of tourists and the local public. The concerned departments, in coordination with the vehicle

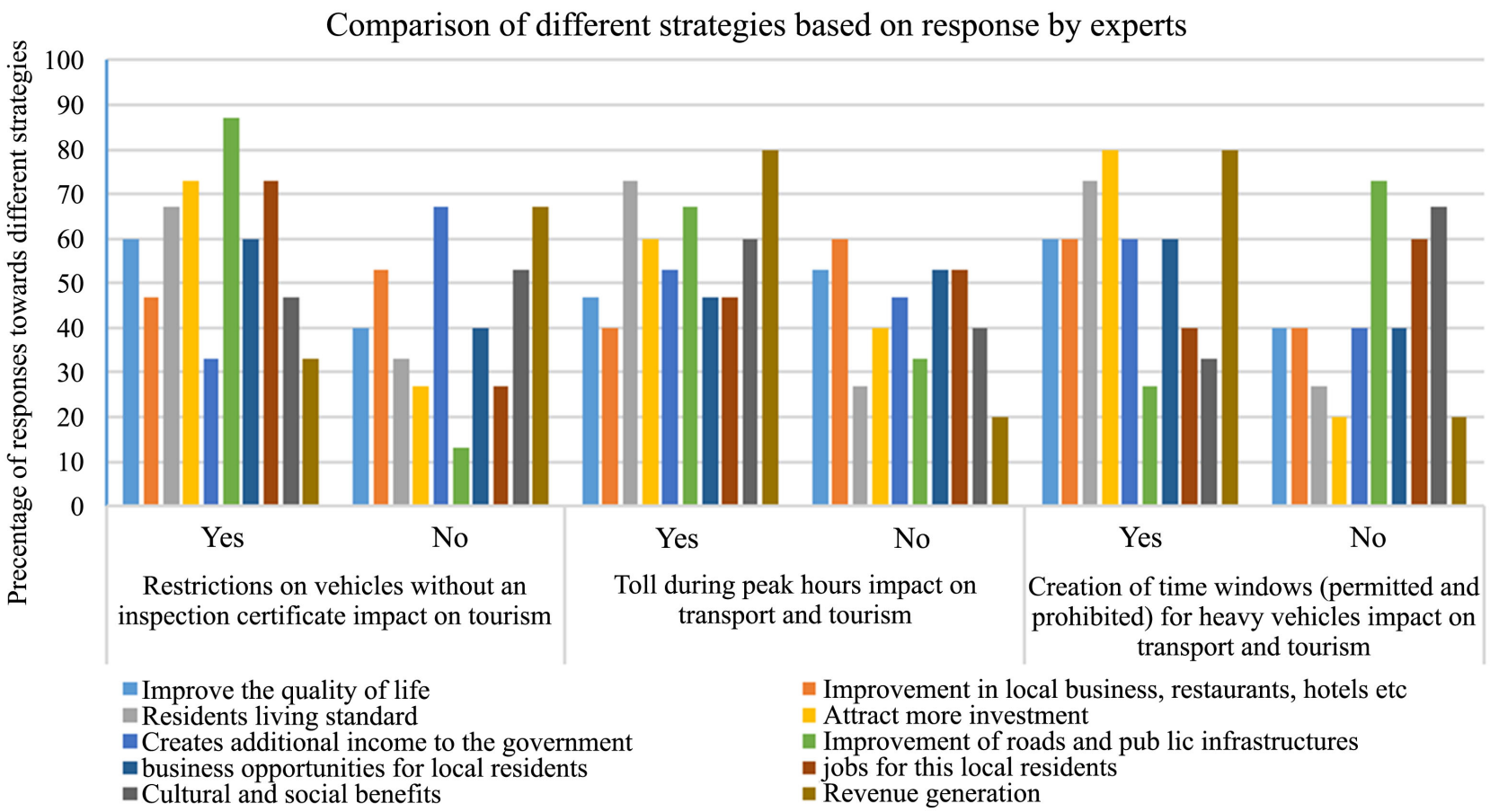

Figure 19. Impact of multiple strategies towards the local community as assessed by the experts (Bars represent the percentage of respondents based on yes and no). 
inspection department, need to check for the policy about banning these vehicles and imposing heavy fines.

The acceptance of the application of toll charges may not be feasible for the locals and residents in the case of Ayubia National Park. But when the visitors were inquired whether they are willing to pay the toll to avoid the situation of congestion, around 113/176 (64\%) of the respondents stated yes. However, there is also $63 / 176(36 \%)$ of the respondents who opposed paying the amount of the toll and agreed to use the alternative routes. Imposing a toll can be a solution. However, the home-based or work-based trips can be excluded from these tolls.

The creation of access time periods for heavy vehicles, as specified in Section 4.2.4, provides the most favorable results. The valuable opinion of experts from the concerned departments also favored this strategy. Schrank also stated heavy vehicles could be forced to travel at slow speeds, and trucks can be required to travel in convoys around protected areas [32].

Apart from the detailed response given by the experts, as explained in Section 4.3, the experts also shared some remarks as discussed further. Strategy 1) Ban on vehicles without inspection certificate: this strategy will increase the number of tourists, quality of transport, lower fuel consumption, improve driving behavior, and reduce the vulnerability of through traffic. The experts opposed strategy 2), application of toll on certain links. The experts highly favored strategy 3) access restriction of heavy vehicles as they were convinced that this strategy would increase the visitors' volume, quality of transport, enhance the sustained flow, and improve the visitors' experience. This measure will not only improve the condition concerning the visitors but also from the local point of view, as it will enhance the quality of life of locals (by reducing pollution, congestion and saving time). The ranking of a tourist destination always has a positive influence on attracting a large number of tourists. The increase in the number of tourists will attract a large amount of investment and create jobs and business opportunities for locals [29].

\section{Conclusions}

The tourism sector needs serious attention, as it can increase the economy of the country. A country like Pakistan has beautiful touristic attractions and also has a lot of national parks. The mobility issues around the connecting roads of Ayubia National Park are full of congestion in peak hours of peak seasons. The increasing number of automotive transportation has created serious congestion on the roads and highways. Along with the failure of the highway system to meet modern needs, the increased income and economic development are putting more burdens on transport facilities. The descriptive analysis helped in the determination of key reasons for mobility issues, i.e., traffic volume because of tourists in peak seasons, vehicles without maintenance certificate, and lower satisfaction level with public transport. The primary data collection also helped in the identification of key strategies to be imposed to improve mobility around the Ayubia National Park. The respondents were of the point of view that the free flow on 
connecting roads decreases because of vehicles without a maintenance certificate. The respondents were asked if they would support the ban on vehicles that don't have a maintenance certificate: 109 (63\%) respondents stated "yes," and only $67(38 \%)$ of the respondents opposed the ban on such type of vehicles. Another strategy was the application of toll on particular links in peak hours of the peak season. Almost $64 \%$ of the respondents agreed that they would be willing to pay the amount of toll if they use the particular links. However, $36 \%$ of the respondents refused to pay the amount of toll and showed the willingness to use alternative routes.

The results obtained from the Transcad analysis show that the implementation of the assumed strategies on the transport network has an impact on reducing the volume to capacity ratio. However, the experts also pointed out that experts consider a ban on vehicles without a certificate as a temporary solution, and implementation of the toll will not work as their long term strategy, as visitors' preferences always overcome the toll price. However, the experts also concluded that these strategies will increase the number of tourists, quality of transport, lower fuel consumption, improve the driving behavior, reduce the vulnerability, improve the local businesses, attract more investment, generate more revenue, and social and cultural benefits will also be achieved. Based on the results generated through Transcad, and the experts' opinion, it can be concluded that the most effective strategy would be the time of day based access restriction to heavy vehicles. It will improve the overall experience of the tourist coming to the Ayubia National Park and also generate a bundle of benefits to the residents.

\section{Acknowledgements}

The authors wish to thank the National Transport research center (NTRC), Pakistan for providing the traffic counts for the connecting areas to Ayubia National Park. We also thank the experts of different departments, e.g., NHA, NTRC, PTDC, GDA, and Planning Commission, for their valuable opinion towards the various elements of research. The authors also like to thank the support received from researchers affiliated with the National University of Sciences \& Technology, National Defense University Islamabd and Hasselt University, especially Muhammad Qadeer, Bilal Latif and Bruno Kochan respectively.

\section{Declaration}

We hereby declare that the work is original, and it is also stated that no potential conflict of interest was reported by the authors.

\section{Funding}

The research work is part of doctoral research. The doctoral research is funded by the Higher Education Commission (HEC), Islamabad, Pakistan.

\section{Conflicts of Interest}

Not applicable. 


\section{References}

[1] Buckley, R. (2012) Sustainable Tourism: Research and Reality. Annals of Tourism Research, 39, 528-546. https://doi.org/10.1016/j.annals.2012.02.003

[2] Del Moretto, D., Colla, V. and Branca, T.A. (2017) Sustainable Mobility for Campsites: The Case of Macchia Lucchese. Renewable \& Sustainable Energy Reviews, 68, 1063-1075. https://doi.org/10.1016/j.rser.2016.02.012

[3] Kaldiyarov, D.A., Kassymova, A.M., Mussina, T.S., Korabayeva, N.B. and Berkinbayeva, Y.E. (2017) An Investigation into the Scientific Methodological Foundations of Transportation Infrastructure in the Tourism Industry. Journal of Environmental Management and Tourism, 8, 1529-1533.

[4] Pettebone, D., Newman, P., Lawson, S. R., Hunt, L., Monz, C. and Zwiefka, J. (2011) Estimating Visitors' Travel Mode Choices along the Bear Lake Road in Rocky Mountain National Park. Journal of Transport Geography, 19, 1210-1221. https://doi.org/10.1016/j.jtrangeo.2011.05.002

[5] Hallo, J.C. and Manning, R.E. (2009) Transportation and Recreation: A Case Study of Visitors Driving for Pleasure at Acadia National Park. Journal of Transport Geography, 17, 491-499. https://doi.org/10.1016/j.jtrangeo.2008.10.001

[6] Smallwood, C.B., Beckley, L.E. and Moore, S.A. (2012) An Analysis of Visitor Movement Patterns Using Travel Networks in a large Marine Park, North-Western Australia. Tourism Management, 33, 517-528. https://doi.org/10.1016/j.tourman.2011.06.001

[7] Díez Gutiérrez, M., Tørset, T., Skjetne, E. and Odeck, J. (2017) Tourist Traffic Simulation as a Protected Area Management Tool. The Case of Serengeti National Park in Tanzania. Tourism Management Perspectives, 22, 54-63. https://doi.org/10.1016/j.tmp.2017.01.005

[8] Han, M. and Yu, Q. (2015) Construction of PSI Model for Tourism Traffic Congestion in Suburban Scenic Area. Journal of Management in Engineering, No. 21, 99.

[9] Repanshek, K. (2018) 10 Best Parks for Traffic Jams. https://www.nationalparkstraveler.org/2018/06/10-best-parks-traffic-jams

[10] Li, X., Meng, F. and Uysal, M. (2008) Spatial Pattern of Tourist Flows among the Asia-Pacific Countries: An Examination over a Decade. Asia Pacific Journal of Tourism Research, 13, 229-243. https://doi.org/10.1080/10941660802280323

[11] Dafermos, S., and Sparrow, F.T. (1971) Optimal Resource Allocation and Toll Patterns in User-Optimised Transport Networks. Journal of transport, Economics and Policy, 5, 184-200.

[12] De Palma, A. and Lindsey, R. (2011) Traffic Congestion Pricing Methodologies and Technologies. Transportation Research Part C: Emerging Technologies, 19, 1377-1399. https://doi.org/10.1016/j.trc.2011.02.010

[13] Curtis, L.F. and Walker, A.J. (1982) 17 Conservation and Protection. The Changing Geography of the United Kingdom, 788, 381.

[14] Lambas, M.E.L. and Ricci, S. (2014) Planning and Management of Mobility in Natural Protected Areas. Procedia-Social and Behavioral Sciences, 162, 320-329. https://doi.org/10.1016/j.sbspro.2014.12.213

[15] Farooque, M. (2011) Transforming Theory and Practice of Environmental Governance-A Case Study of Ayubia National Park, Pakistan. The University of Waterloo, Waterloo.

[16] Afza, R. (2016) Phytosociological Indicators for Pheasant's habitat Use and Occurrence in Ayubia National Park. PhD Thesis, Hazara University Mansehra, Manse- 
hra.

[17] Mani, A. (1981) The Climate of Himalaya. The Himalaya: Aspects of Change. Oxford University Press, New Delhi.

[18] Afza, R. (2006) Linkages between Forest Conservation and Medicinal Plants of Ayubia National Park: Prospective and Constrains. PhD Thesis, M. Phil Dissertation, Department of Plant Sciences, Quaid-e-Azam University, Islamabad.

[19] Javed, A., Khan, A.S., Qadir, A., Khan, S. and Shehzad, S. (2019) Comparative Analysis of Water Quantity and Quality in Relation to Vegetation Cover in Himalayan Moist Temperate Forests of Galliyat. International Journal of Economic and Environmental Geology, 7, 46-53.

[20] (2020) CTP Formulates a Plan to Tackle Traffic Congestion in Murree. PakWheels Blog.

https://www.pakwheels.com/blog/ctp-formulates-a-plan-to-tackle-traffic-congestio n-in-murree/

[21] (2017) Murree Sees Large Influx of Holidaymakers. The News.

https://www.thenews.com.pk/print/260706-murree-sees-large-influx-of-holidaymak ers

[22] Fakhar, W.R. (2016) Rain, Tourists Cause Traffic Jams in Murree. DAWN. COM. http://www.dawn.com/news/1269846

[23] Ullah, F. (2014) 23\% of Educated People Drive without a License in Pakistan. PakWheels Blog.

https://www.pakwheels.com/blog/23-educated-people-drive-without-license-pakista $\underline{\mathrm{n} /}$

[24] Zhao, X., Xu, Z. and Yu, Y.F. (2016) Countermeasures of Developing Smart Tourism in Transportation Hub City Based on Big Data.

[25] Shaker, M., Hermans, E., Cops, V., Vanrompay, Y., Adnan, M., Maes, R. and Yasar, A.-H. (2020) Facilitating Hikers' Mobility in Protected Areas through Smartphone App: A Case of the Hoge Kempen National Park, Belgium. Personal and Ubiquitous Computing. https://doi.org/10.1007/s00779-020-01367-6

[26] Qureshi, D.O.M., Afridi, D.S.A. and Hafeez, M.A. (2019) Geometric Loading Patterns of Goods Vehicles in Pakistan. 60.

[27] Ali, M.S., Adnan, M., Noman, S.M. and Baqueri, S.F.A. (2014) Estimation of Traffic Congestion Cost-A Case Study of a Major Arterial in Karachi. Procedia Engineering, 77, 37-44. https://doi.org/10.1016/j.proeng.2014.07.030

[28] Diamond, I.R., et al. (2014) Defining Consensus: A Systematic Review Recommends Methodologic Criteria for Reporting of Delphi Studies. Journal of Clinical Epidemiology, 67, 401-409. https://doi.org/10.1016/j.jclinepi.2013.12.002

[29] Goffi, G., Cucculelli, M. and Masiero, L. (2019) Fostering tourism Destination Competitiveness in Developing Countries: The Role of Sustainability. Journal of Cleaner Production, 209, 101-115. https://doi.org/10.1016/j.jclepro.2018.10.208

[30] Ribeiro, M.A., Pinto, P., Silva, J.A. and Woosnam, K.M. (2017) Residents' Attitudes and the Adoption of Pro-Tourism Behaviours: The Case of Developing Island Countries. Tourism Management, 61, 523-537. https://doi.org/10.1016/j.tourman.2017.03.004

[31] Sugimoto, K., Ota, K. and Suzuki, S. (2019) Visitor Mobility and Spatial Structure in a Local Urban Tourism Destination: GPS Tracking and Network Analysis. Sustainability, 11, 919. https://doi.org/10.3390/su11030919

[32] Schrank, D. and Lomax, T. (2009) 2009 Urban Mobility Report. 